\title{
A long winter for the Red Queen: rethinking the evolution of
}

\section{seasonal migration}

\author{
Benjamin M. Winger ${ }^{*}$, Giorgia G. Auteri, Teresa M. Pegan \& Brian C. Weeks \\ Museum of Zoology and Department of Ecology and Evolutionary Biology, University of \\ Michigan, Ann Arbor, MI 48109, USA
}

*Author for correspondence (E-mail: wingerb@umich.edu; Tel.: 1-734-763-3379).

\begin{abstract}
This paper advances an hypothesis that the primary adaptive driver of seasonal migration is maintenance of site fidelity to familiar breeding locations. We argue that seasonal migration is therefore principally an adaptation for geographic persistence when confronted with seasonality - analogous to hibernation, freeze tolerance, or other organismal adaptations to cyclically fluctuating environments. These ideas stand in contrast to traditional views that bird migration evolved as an adaptive dispersal strategy for exploiting new breeding areas and avoiding competitors. Our synthesis is supported by a large body of research on avian breeding biology that demonstrates the reproductive benefits of breeding-site fidelity. Conceptualizing migration as an adaptation for persistence places new emphasis on understanding the evolutionary tradeThis is the author manuscript accepted for publication and has undergone full peer review but has not been through the copyediting, typesetting, pagination and proofreading process, which may lead to differences between this version and the Version of Record. Please cite this article as doi: $10.1111 /$ brv.12476
\end{abstract}

This article is protected by copyright. All rights reserved. 
offs between migratory behaviour and other adaptations to fluctuating environments both within and across species. Seasonality-induced departures from breeding areas, coupled with the reproductive benefits of maintaining breeding-site fidelity, also provide a mechanism for explaining the evolution of migration that is agnostic to the geographic origin of migratory lineages (i.e. temperate or tropical). Thus, our framework reconciles much of the conflict in previous research on the historical biogeography of migratory species. Although migratory behaviour and geographic range change fluidly and rapidly in many populations, we argue that the loss of plasticity for migration via canalization is an overlooked aspect of the evolutionary dynamics of migration and helps explain the idiosyncratic distributions and migratory routes of long-distance migrants. Our synthesis, which revolves around the insight that migratory organisms travel long distances simply to stay in the same place, provides a necessary evolutionary context for understanding historical biogeographic patterns in migratory lineages as well as the ecological dynamics of migratory connectivity between breeding and non-breeding locations.

Key words: geographic range, evolution of migration, site fidelity, philopatry, migratory connectivity, seasonality, dispersal.

\section{CONTENTS:}

I. Introduction 
II. Definitions of 'migration', 'dispersal', and the 'evolution of migration' ....................5

III. A brief history of theory on the evolution of bird migration ............................................ 8

(1) Traditional paradigms for the evolution of migration tether biogeographic origin with

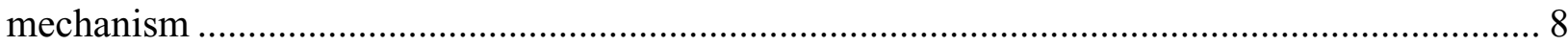

(2) A geographically agnostic framework for the evolution of migration.......................... 12

IV. Adaptations to fluctuating environments, site fidelity, and the evolution of migration ......... 15

(1) Migration is an adaptation for persistence in seasonal environments ........................ 15

(2) Breeding site fidelity, not exploration, underlies the evolution of migration ................ 21

V. Reconciling seasonal migration and geographic range evolution...................................... 25

(1) Migration evolves similarly regardless of biogeographic origin .............................. 26

(2) Dispersal, tropical niche conservatism and the colonization of seasonal environments. 28

(3) The evolution and persistence of disjunct geographic ranges in long-distance migrants 31

VI. Synopsis: a long winter for the Red Queen ................................................................ 36

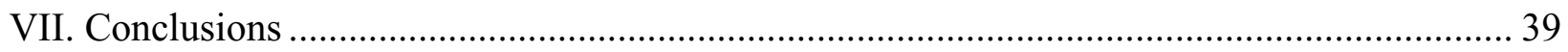

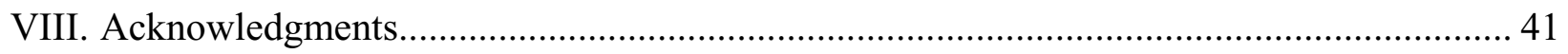

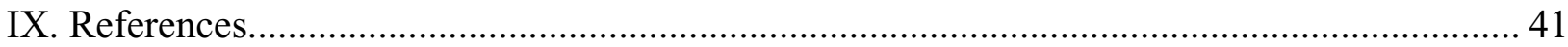

\section{INTRODUCTION}

When an animal finds a suitable location for reproduction, there are benefits to continuing to breed in that location year after year. The challenges of resource acquisition,

This article is protected by copyright. All rights reserved. 
predator evasion and interactions with competitors are lessened by intimate familiarity with a breeding territory, whereas leaving a territory puts an individual at risk of losing the location to a competitor and also subjects it to an unfamiliar terrain containing different parasites, pathogens and predators (Pärt, 1995; Bensch et al., 1998; Doligez \& Pärt, 2008; Altizer, Bartel \& Han, 2011; Bonte et al., 2012). Yet, every year, billions of adult animals leave the localities where they invested heavily in the acquisition and defence of a breeding territory to journey across the globe. Some will next breed in new sites wherever and whenever resources allow, but among birds, these nomadic species are a minority (Winkler, 2005). Rather, most of the birds that vacate their breeding territories in one season will, in a matter of months, attempt to return to the same locales where they bred before. These are the migratory species, whose seasonal drive towards specific breeding sites is all the more remarkable given the long distances they travel between breeding events.

Seasonal migration can be understood intuitively as a persistence strategy, allowing an organism to achieve the benefits of maintaining a breeding territory while avoiding the fitness or survival cost of a resource-depleted season in that location (Bell, 2000; Alerstam, Hedenstrom \& Akesson, 2003; Cresswell, Satterthwaite \& Sword, 2011). Migration is just one of many possible adaptive strategies that enable persistence and continued reproduction in seasonal environments. Other organisms employ analogous strategies for coping with pronounced seasonality as diverse as hibernation, diapause, changes in diet and social behaviour, or physiological changes to improve freeze tolerance. As with migration, the complexity and degree of other adaptations to 
fluctuating environments is predicted by the severity of seasonality in different regions (Williams et al., 2017), but all organisms found in seasonal environments must have some adaptation for predictable intra-annual changes in climate and food resources or they will not persist. Seasonal migration and other adaptations for seasonality, such as hibernation, thus have a similar adaptive function: to maintain access to breeding territories that experience predictable periods of resource depletion.

Contrary to this perspective, seasonal migration in birds has often been viewed not as having evolved to facilitate persistence in a seasonal environment, but rather as a colonization strategy for finding new breeding sites with fewer competitors, less formidable predators and more abundant food resources than supposedly more crowded and dangerous tropical locales (Cox, 1968, 1985; Levey \& Stiles, 1992; Safriel, 1995; Rappole \& Jones, 2002). This framework has resulted in a problematic linkage of the geographic origins of lineages that contain migratory species and the mechanisms proposed to explain the evolution of migratory behaviour in birds (Salewski \& Bruderer, 2007; Winger, Barker \& Ree, 2014). Moreover, in the ornithological literature, this perspective has typically precluded migration in birds from being considered within a broader context of other organismal - and even other avian - adaptations to seasonality and fluctuating environments.

In this synthesis, we advocate a change of perspective to view the evolution of seasonal migration in birds principally as an adaptation for persistence in a seasonal environment analogous to alternative adaptations such as hibernation. This view provides an improved 
framework for understanding both the mechanisms by which bird migration evolves as well as its inherently complex relationship with the evolution of geographic ranges. Although migration is widespread and highly variable across many groups of animals (Dingle, 2006; Shaw, 2016), we focus on the migrations of birds and in particular their regular, cyclical, seasonal migrations. An improved understanding of bird migration and its influence on avian biogeographical patterns will inform the study of migration in other animal groups, including the accentuation of differences in migratory strategies across taxa.

\section{DEFINITIONS OF 'MIGRATION', 'DISPERSAL', AND THE 'EVOLUTION OF MIGRATION}

We consider migration a regular, seasonal round-trip movement between a region where young are reared (a 'breeding range') and a non-breeding region or regions. By contrast, dispersal, a phenomenon found in all species to some degree, is a one-way movement of an individual between breeding locations. In birds, even those with long-distance migrations, dispersal typically occurs over short distances, as birds have high fidelity to their breeding sites. Usually, it is only the first dispersal event of a bird's lifetime - from the location in which a bird was hatched to where it first breeds (natal dispersal) - that occurs over any appreciable distance. In subsequent breeding seasons, an individual bird is likely to return to the same breeding site that it used in the previous year. Philopatry refers specifically to the tendency to return to natal sites, whereas breeding site fidelity refers to the tendency to return to the site where an adult

This article is protected by copyright. All rights reserved. 
individual bred previously. Individuals may also maintain fidelity to wintering and stopover locations or change these locations throughout their lifetimes; thus, changes to non-breeding sites throughout the life of an individual could be considered dispersal, but for the sake of consistency with previous literature we use the term 'dispersal' to refer only to changes in breeding location.

Migratory movements are highly variable across birds. Species in which only some individuals within a population migrate or wherein populations are variable in migratory behaviour are known as partial migrants, in contrast to complete or obligate migrants. The cyclical regularity of seasonal migration stands in contrast to facultative migrations such as nomadism and irruption, both of which are irregular phenomena. Nomadic behaviour occurs in species that vary their breeding sites and often their timing of breeding according to the unpredictable availability of resources, resulting in irregular movements of portions of the population. Irruptive movements occur when birds move away from their breeding sites during times of low resource availability, but unlike seasonal migration, irruption occurs irregularly depending on food resources and population dynamics. In some species, irruption and nomadism are difficult to distinguish, and in other species the lines may be blurred between migration and nomadism or irruption (Eyres, Böhning-Gaese \& Fritz, 2017). Nomadism is often considered to be a variation of migration (e.g. Newton, 2010), but the differences in the role of breeding-site fidelity between these two behaviours - in nomadism, a repeated movement to a new breeding territory, and in migration, a repeated return to a single breeding location - suggests that nomadism is perhaps best thought of as sequential dispersal (Boyle, 2018). 
We refer frequently to the 'evolution of migration'. Zink $(2002,2011)$ has cautioned that the 'evolution of migration' in a lineage should not be confused with the 'origin' of migratory behaviour. Zink suggests that because migration is likely an ancient aspect of avian biology that has been gained and lost repeatedly in the avian tree of life through selection on existing genetic composition as opposed to de novo evolution in different lineages, that the phrase 'evolution of migration' is problematic. We agree with Zink's point that the appearance of migratory behaviour in a population that was previously sedentary does not mean that migration originated de novo. When using the phrase 'evolution of migration', we simply mean the appearance or intensification of migratory behaviour in a population or lineage that was previously sedentary or less migratory, regardless of underlying molecular evolution or putative homology.

\section{A BRIEF HISTORY OF THEORY ON THE EVOLUTION OF BIRD MIGRATION \\ (1) Traditional paradigms for the evolution of migration tether biogeographic origin with} mechanism

The inherently complex geography of seasonal migration has led to much debate about how to reconcile mechanistic aspects of the evolution of bird migration with the biogeographic history of migratory lineages (Zink, 2002; Salewski \& Bruderer, 2007; Winger et al., 2014). Theories on the evolution of bird migration have already been extensively reviewed (e.g. Gauthreaux, 1982; Rappole \& Jones, 2002; Salewski \& Bruderer, 2007; Boyle, 2018), and 
several themes have emerged that have had a persistent influence on our understanding of the relationship between the evolution of migration and geographic range dynamics. Because the most dramatic bird migrations occur across latitudes, the evolution of bird migration has often been framed as a 'southern-home' versus 'northern-home' debate, which can be generalized to a 'tropical home' versus 'temperate home' framework to include austral migration. According to the tropical home paradigm, contemporary migrations between temperate and tropical latitudes evolved in tropical birds as a mechanism to take advantage of bountiful resources and fewer competitors in temperate regions (Rappole, 1995; Safriel, 1995; Rappole \& Jones, 2002). These ideas stem largely from Cox (1968), who argued that seasonal migration evolves in tropical, sedentary birds that are driven by competition to move into adjacent, higher latitude habitats to breed. Cox (1968, p. 183) wrote, "given permissive conditions, selection should favour any...variation leading to incipient migratory movements into adjacent areas if the reduction in total competition (intraspecific and interspecific) allows greater survival or reproduction...than in the original [sedentary] range." In other words, the temperate zone was considered more favourable for breeding than the tropics and organisms should evolve to migrate there.

Importantly, Cox suggested that the first migrations ("incipient migratory movements") involved movements out of tropical or subtropical areas to colonize new breeding locations in more seasonal, temperate areas. Although it was implicit that the harsh, resource-depleted winters in the breeding ranges of temperate migratory birds forced them to return every year to the tropics, 
Cox considered a lack of resources in the winter to be of lesser importance to the evolution of migration than the bounty of resources and lack of competitors in temperate-latitude summers.

The related but distinct 'evolutionary precursor' hypothesis also envisioned migration evolving out of the tropics via an initial migration to a higher latitude breeding location where reproductive success would be greater, and suggested that certain diets or habitats predisposed some tropical lineages to become migratory (Levey \& Stiles, 1992; Chesser \& Levey, 1998; Boyle \& Conway, 2007). Specifically, frugivory and nectarivory were seen as 'evolutionary precursors' to seasonal migration, as was preference for edge habitats, because the search for these spatially ephemeral foods and habitats might lead to longer distance movements (Levey \& Stiles, 1992). As with the other tropical home hypotheses, the evolutionary precursor hypothesis envisioned the incipient migratory movements in a sedentary tropical ancestor as occurring from ancestral tropical breeding areas to more seasonal, higher latitude breeding areas. A return trip to the tropics was implicitly driven by a lack of resources in high-latitude winters but was not viewed as having stimulated the evolution of migration.

Support for tropical home theories increased in parallel with the growth of ecological knowledge about tropical migrants on their wintering grounds. As tropical ecologists learned that Neotropical migratory birds that breed at high latitudes have intricate ecological relationships with resident tropical species during northern winters (e.g. Keast \& Morton, 1980; Holmes, Sherry \& Reitsma, 1989), the conviction strengthened that these migrants must have originated in the tropics (Levey \& Stiles, 1992; Rappole \& Tipton, 1992; Levey, 1994). Recognition that 
short-distance movements (such as altitudinal migration) are much more common among tropical birds than previously supposed also bolstered support for tropical origins of migration (Levey, 1994; Jahn, Levey \& Smith, 2004; Boyle \& Conway, 2007). In recent literature, tropical home theories have frequently been presented as the consensus view (e.g. Jahn et al., 2004; Pulido, 2007; Bisson, Safi \& Holland, 2009), resulting in the widespread framing of longdistance migration as a strategy to escape competition in the crowded tropics or to increase reproductive success through exploitation of energy resources during high-latitude summers (Rappole \& Jones, 2002; Guttal \& Couzin, 2010; Somveille, Rodrigues \& Manica, 2015, 2018b; Turbek, Scordato \& Safran, 2017).

Although seasonality has clearly been recognized as an important aspect of migration (Alerstam et al., 2003), theories of the evolution of migration involving selection to avoid the harsher, resource-limited aspects of seasonal environments (as opposed to exploit beneficial aspects) have received surprisingly limited consideration, considering the intuitiveness of this idea. Alfred Russel Wallace (Wallace, 1874) and Ernst Mayr [Mayr \& Meise (1930), in Salewski \& Bruderer (2007)] suggested that a lack of resources in temperate winters drove the evolution of migration, but few recent authors other than Bell $(2000,2005)$ and Salewski \& Bruderer (2007) have championed these beliefs. Retreat from deteriorating seasonal conditions in temperate winters has been viewed more as an incidental consequence of migration, rather than a cause. 
Resistance to viewing seasonality as the principal driver of the evolution of migration, despite the obvious connection, was in part due to the tethering of the biogeographic origin of migration (i.e. tropical versus temperate home) with the selective pressures that stimulate migration (Zink, 2002; Salewski \& Bruderer, 2007). That is, if a migratory lineage was thought to be of tropical origin, it was assumed that the selection pressures leading to migration must have occurred in the tropics (e.g. Rappole, 1995; Rappole \& Jones, 2002). However, our understanding of the biogeographic origins of migratory lineages has been obscured by the complex biogeography inherent to seasonal migration (Joseph, Lessa \& Christidis, 1999; Winger et al., 2014). Consequently, progress towards clarifying the selective pressures underlying the evolution of migration has been hindered by confusion surrounding the relationship between the geographic origins of migratory lineages and the mechanism by which migration evolves.

\section{(2) A geographically agnostic framework for the evolution of migration}

Salewski \& Bruderer (2007) advanced theory on the evolution of migration considerably by articulating the major shortcomings of the 'southern' or 'tropical home' theories and calling into question the necessity for a connection between the biogeographic origin of migratory lineages and the evolution of migration. The central problem they identified was a conflation of dispersal and migration in previous theories. Dispersal is a movement whereby individuals search for and find new breeding sites (see Section II), and the geographic range expansion of a taxon is an emergent property of successful dispersal of individuals. High population density 
may select for more highly dispersive behaviour, suggesting a connection between competition and dispersal patterns (Matthysen, 2005; Cote et al., 2017). However, density-dependent dispersal is distinct from seasonal migration; that is, there is not a clear conceptual basis for why high competition in a region would lead directly to regular movement not only away from, but also back to, the ancestral region, as suggested by tropical home theories (Bell, 2005; Salewski \& Bruderer, 2007). Furthermore, the rationale underlying the expectation that there are adaptive benefits for migration away from the tropics to new breeding sites in temperate regions rested on the supposition that the reproductive success of birds is greater at higher latitudes. Such lifehistory theory, which was based largely on clutch-size variation across latitudes, is now known to be an oversimplification; relying only on clutch size or fecundity to define reproductive success overlooks nuances of avian developmental biology and mortality across latitudes that create trade-offs between lifetime versus single-season reproductive success (Martin, 2004, 2015; Salewski \& Bruderer, 2007).

To disentangle the evolution of migration from the biogeographic history of migratory lineages, Salewski \& Bruderer (2007) proposed the geographically agnostic 'dispersal-migrationtheory' in which regular dispersal from less-seasonal areas into more-seasonal areas, regardless of geographic orientation, precedes and facilitates the evolution of migratory behaviour. That is, when individuals from a sedentary population disperse away from their natal territories and establish in new locations, they may colonize adjacent areas that are more seasonal than the ancestral region. Natural selection would then favour the evolution (or expression; see Section II) 
of migration in the newly colonized region as an escape strategy to avoid the harsher, resourcedepleted season (Fig. 1). Thus, migration and geographic range evolve in tandem. That selection for migration in a seasonal environment should increase the proportion of migrants in a population was not a new idea - this is the basis of the 'threshold model' for the evolution of migration (Berthold, 1999). However, the influence of dispersal, rather than migration, in facilitating the expansion of populations into more seasonal environments had not been fully articulated. Consequently, prior to Salewski \& Bruderer (2007), the threshold model had not been adequately contextualized with respect to the biogeographic changes that can accompany the evolution of migration.

Salewski \& Bruderer’s (2007) ‘dispersal-migration-theory’ thus provided a useful entry point for conceptualizing the evolution of migration and its relationship to the evolution of geographic range. Here, we build on the ideas that migration originates either through dispersal into seasonal environments or through in situ changes in seasonality through time (Fig 1; Bruderer \& Salewski, 2008; Louchart, 2008) by adding two critical components that typically have not been connected to the evolution of migration: (1) we highlight the importance of viewing migration not only as an adaptation for persistence in a seasonal environment but as one of many alternative organismal adaptations to seasonality; and (2) we posit that breeding-site fidelity - a phenomenon observed widely in many animal taxa - underlies the origin and maintenance of migratory behaviour as an adaptive strategy. This latter point stands in contrast to the perspective that aligns the evolution of migration with exploratory dispersal to new 
breeding sites, rather than site fidelity. We then discuss how this new perspective on the adaptive function of migration represents an important but largely overlooked consideration for understanding biogeographic patterns in migratory taxa such as birds, including the idiosyncratic and extreme range disjunctions of long-distance migratory species that have long perplexed biogeographers.

\section{ADAPTATIONS TO FLUCTUATING ENVIRONMENTS, SITE FIDELITY, AND THE EVOLUTION OF MIGRATION}

\section{(1) Migration is an adaptation for persistence in seasonal environments}

Reviews of bird migration often begin by giving credit to Aristotle for the earliest known scientific treatment of the topic, to highlight humanity's long fascination with the migrations of birds (Thomson, 1926; Wetmore, 1930; Gauthreaux, 1980; Milner-Gulland, Fryxell \& Sinclair, 2011; Boyle, 2018). Some authors go on to give Aristotle a more ignominious attribution by mentioning that he was the first writer to hypothesize that birds had a different strategy for surviving the winter: hibernation. Throughout the Middle Ages and into the nineteenth century, the belief persisted that swallows hibernated in the mud of rivers and marshes (Thomson, 1926). As twentieth century ornithologists learned more about bird migration, theories of hibernation were dismissed with derision, and Aristotle's association with advancing such theories was regarded as something of an embarrassing lapse in omniscience. For example, Wetmore (1930) discussed avian hibernation in a section titled "Theories of Migration: Superstitious Beliefs", in 
stark contrast to the next section of his book, "Scientific Hypotheses of Migration". Thomson (1926, p. 23) wrote with respect to avian hibernation that with "better knowledge of birdmigration [sic] it is now possible to dismiss these theories as lightly as those once popular notions that birds became transformed into other species in winter or that there is migration between the Earth and the Moon."

Today, the scientific literature on the evolution of bird migration almost never mentions hibernation as an alternative to migration - not even as a target of ridicule - because we now know with certainty that birds migrate long distances and we understand that subterranean hibernation is a decidedly non-avian behaviour. Yet, it turns out that one species of bird (the Common Poorwill, Phalaenoptilus nuttallii) sometimes hibernates in the high, cold deserts of western North America (Jaeger, 1948, 1949; Brigham, 1992). Other avian species (albeit from only a handful of lineages) undergo daily torpor (Geiser, 2004). Many more species have shallower facultative hypothermic responses for energy conservation (McKechnie \& Lovegrove, 2002; Ruf \& Geiser, 2015; Douglas, Cooper \& Withers, 2017) or adjust metabolic rate to survive cold temperatures (Swanson \& Garland, 2009; Swanson \& Vézina, 2015; Stager et al., 2016). Beyond migration and adjustments to metabolic rate, avian adaptations to withstand cold temperatures are diverse. For example, 6-g kinglets survive boreal winter nights at temperatures of $-40^{\circ} \mathrm{C}$ by huddling together; grouse and ptarmigan make snow burrows; cavity-nesting birds may roost within their nest holes, sometimes socially; many finches have evolved flexible breeding schedules and entirely granivorous diets that allow them to exploit food resources year- 
round at high latitudes; and certain lineages such as corvids are capable of profound seasonal shifts in their social behaviour, foraging, and diet (Stutchbury \& Robertson, 1990; Heinrich, 2003a, b; Gill, 2007).

By banishing avian hibernation to the realm of science fiction, early thinkers on the evolution of migration divorced bird migration from this rich diversity of other physiological and behavioural adaptations to seasonal environments - adaptations that are important for understanding bird migration because they represent the necessary alternatives to migratory behaviour if a lineage is to persist in a highly seasonal region (Lyman et al., 1982; Sol, Lefebvre \& Rodriguez-Teijeiro, 2005). This decoupling of migration from other adaptations to seasonality was perpetuated throughout the 20th century literature on bird migration. Because bird migration between temperate and tropical latitudes was conceptualized as a movement stimulated initially by in situ tropical selection pressures (e.g. Cox, 1985; Levey \& Stiles, 1992), as opposed to a behaviour conferring a selective advantage in a population found in a seasonal environment, migration was not regarded as an adaptation for persistence akin to other organismal adaptations to seasonality.

We propose that a more useful framework recognizes that migration is an adaptation for increasing fitness in the face of fluctuations in climate or resources. Because of this, the proportion of migratory species in a region scales (broadly) with the severity of resource fluctuations (Somveille et al., 2013, 2018b). That is, short-distance migrations occur in the tropics and are driven by seasonal dynamics such as wet-dry cycles, but the greater severity of 
seasonality at higher latitudes drives the evolution of migrations that are not only more extreme in geographic scope but also comprise a larger proportion of the regional avifauna (Gómez et al., 2016). Furthermore, the concept that unites migration with other organismal adaptations to seasonality is the recognition that the absence of migration in a highly seasonal environment is not, in itself, a viable alternative to migration. Rather, the absence of migration in a species that lives in a highly seasonal environment necessarily signifies the existence of an alternative adaptation to seasonality in that species. Likewise, in partially migratory species, individuals that do not migrate or that migrate facultatively must also have adaptations to overcome the consequences of not migrating (Chapman et al., 2011; Fudickar et al., 2016). Depending on the ecological context, the absence of migration may require a profound behavioural or physiological shift during the annual cycle (such as social roosting in territorial species or dietary shifts to granivory in insectivores) or relatively subtle changes (such as an adjustment in the species of fruit consumed at different times of year in the tropics; Boyle, Conway \& Bronstein, 2010). Recognition that obligate, long-distance migration is one of several possible migratory responses to seasonality (including altitudinal or facultative migrations), but moreover that all migratory movements collectively represent an alternative to yet other adaptations to seasonality that do not involve geographic escape, is a necessary context for understanding how and why different adaptations to fluctuating environments evolve.

Given the diversity of possible responses to seasonality, why is migration the most common strategy in birds, and why does migration evolve more frequently in some lineages than 
others? Certainly, the vagility of birds and other volant organisms predisposes them for migration. Yet, birds have great variation in the degree to which they use their wings for locomotion (Heers \& Dial, 2015), suggesting the commonness of migration among birds is more reflective of the evolutionary lability of the avian flight apparatus (including associated metabolic, physiological and neurological accommodations for long-distance flight) than the existence of a flight apparatus per se. Such evolutionary flexibility of the flight apparatus stands in apparent contrast with the lability of another structure possessed by all birds: the brain. Sol et al. $(2005,2010)$ provided evidence for larger brains in resident versus migratory species, and argued that year-round persistence in a highly seasonal environment requires a larger brain that allows for greater flexibility in diet and behaviour necessary to survive in a resource-depleted landscape. This idea has been debated, in part due to the difficulty of determining whether the smaller brains of migrants are truly representative of neurological deficiencies or are a consequence of the energetic demands of migration selecting for smaller crania (Winkler, Leisler \& Bernroider, 2004; Pravosudov, Sanford \& Hahn, 2007; Sayol et al., 2016; Fristoe, Iwaniuk \& Botero, 2017). Additionally, migratory species may also change their diets throughout the year (e.g. Gómez et al., 2018). Nevertheless, many bird species that maintain year-round occupancy in the environments with the greatest fluctuation in resource base are those that have evolved neurological adaptations for food caching (Sherry et al., 1989) or extreme flexibility in diet, often facilitated by complex social interactions (Marzluff, Heinrich \& Marzluff, 1996). As migration is a much more common adaptation to seasonality in birds, transitions to a highly 
migratory lifestyle seem more likely to evolve quickly and repeatedly than evolutionary changes in neurobiology that would facilitate alternative behavioural flexibilities for persistence in environments with extreme competition for depleted resources. Parallel arguments can likely be made for the relative rarity of other behavioural and physiological adaptations to seasonality, such as hibernation. Although the reasons why adaptive hypothermia is rare in birds are not well understood (McKechnie \& Lovegrove, 2002; Ruf \& Geiser, 2015), the high evolvability of avian vagility combined with a relatively low flexibility of metabolic rates in birds has likely led to migration evolving more commonly in birds than, for example, small mammals or amphibians. Other highly vagile organisms such as bats and insects have also evolved migration repeatedly, but combine their migrations with other strategies such as torpor and dormancy in complex ways whose evolutionary history demands further investigation (Bisson et al., 2009; Shaw, 2016)

There is a great deal we have yet to learn about why certain adaptations for seasonality evolve only in some lineages, or manifest only in some individuals, and what evolutionary tradeoffs are involved in different strategies. To date, discussions of these trade-offs have mostly taken place in the literature on partial migration, in the context of understanding intraspecific variation in migratory behaviour among individuals (e.g., Ketterson \& Nolan, 1982; Boyle, 2011; Chapman et al., 2011; Zúñiga et al., 2017). Interspecific comparisons, framed in the context of alternative but functionally similar adaptations for persistence in a seasonal environment, are also important for understanding the evolution of migration and other adaptive strategies for seasonality. For example, the 16-g Blackpoll Warbler (Setophaga striata) flies four 
days nonstop from breeding grounds in the boreal forest to winter locations in the Amazon (Fig. 2; Deluca et al., 2015). By contrast, the 6-g Golden-crowned Kinglet (Regulus satrapa) often spends the northern winter near these same boreal breeding grounds (Fig. 2; Heinrich, 2003a). Both of these strategies, migration and residency, involve profound seasonal shifts in diet, physiology, behaviour and pathogenic regimes. The long-distance migration of the Blackpoll Warbler is rightly celebrated as an extraordinary feat of endurance, but this strategy has actually evolved more frequently across the avian tree of life than the persistence strategy used by the kinglet. Recognition that seasonal migration is one of several possible adaptations for persistence in any seasonal environment promises to advance our understanding of the evolutionary tradeoffs between migratory behaviour and other adaptations to resource fluctuations in birds and other organisms.

\section{(2) Breeding site fidelity, not exploration, underlies the evolution of migration}

It is intuitive that an animal might leave an area when climatic conditions become unfavourable and resources scarce: for some populations (or for some individuals in populations with mixed migratory strategies), leaving a region in the non-breeding season offers a greater probability of survival than staying, despite the costs of migration (Lack, 1968; Zúñiga et al., 2017; Dokter et al., 2018). Indeed, migration is typically described as a resource-tracking strategy (Alerstam et al., 2003; Alerstam \& Bäckman, 2018; Somveille et al., 2018b). But why should migrants return the following spring, rather than settle on their non-breeding grounds or 
disperse to a new breeding location with yet better resources, as do nomadic species? This question has usually been answered by defining migration as an endogenously driven round trip, but a satisfying exploration of the selective forces that led to this endogenous control has been elusive (Berthold, 1999; Salewski \& Bruderer, 2007).

We propose that a central conclusion from a long history of research on the breeding biology of migratory birds provides the needed explanation for the mechanism underlying selection for a regular, round-trip migration: it is the increased reproductive success leveraged by efficiently returning to successful breeding sites, as opposed to the drive to disperse to potentially better breeding sites outside a species' range (as predicted by tropical home theories), that underlies the endogenous control of seasonal migration as a round trip. Many studies have shown that individual birds that arrive quickly at their breeding grounds have higher reproductive success than birds that arrive and begin nesting late (Perrins, 1970; Price, Kirkpatrick \& Arnold, 1988; Marra, Hobson \& Holmes, 1998; Kokko, 1999; Norris et al., 2004; Charmantier \& Gienapp, 2014). Arriving on time to the breeding grounds should be easier when the location is known, resulting in selection for fidelity to successful breeding sites in returning breeders (Greenwood \& Harvey, 1982; Payne \& Payne, 1993; Pärt, 1995; Hoover, 2003; Hansson, Bensch \& Hasselquist, 2004). Individuals that do not migrate thus gain the reproductive advantage of staying near to their breeding sites or having more time to search for nearby sites (Chapman et al., 2011; Kokko, 2011; Zúñiga et al., 2017). But individuals that migrate are also under strong selection to return rapidly to known breeding regions and re- 
establish territories (Kokko, 1999), leading to migrations that tend to be faster in in spring than in autumn (Horton et al., 2016).

Research on the wintering ecology of migratory birds suggests that individual fidelity to wintering sites is also an important component of migration in some species, with winter site fidelity increasing over-winter survival and body condition (Holmes et al., 1989; Holmes \& Sherry, 1992; Cresswell, 2014; Shizuka et al., 2014; Blackburn \& Cresswell, 2016). Importantly, behavioural and ecological traits that bolster over-winter survival and condition of individuals must translate to increases in reproductive success to be selected for across generations.

Therefore, although the ecological dynamics of the non-breeding season dictate many important population-specific details of migratory behaviour, we argue that natural selection fundamentally acts on the non-breeding portions of the annual cycle to support an efficacious return to familiar breeding grounds in spring. Indeed, increased winter survival and fitness has been shown in some studies to bolster reproductive success the following spring (e.g. Sillett, Holmes \& Sherry, 2000; Norris et al., 2004), highlighting the importance of full-annual-cycle ecological research for understanding the population dynamics, migratory routes, and biogeography of migratory birds (Marra et al., 2015).

Rapid changes to some migratory species' ranges that have been observed over recent decades could lead to the conclusion that migratory species are less site faithful than we have claimed here. However, in species in which such geographic shifts have been studied in detail, such as the Icelandic Black-tailed Godwit (Limosa limosa islandica), range expansions typically 
occur via the dispersal of young birds to their first breeding sites (i.e. natal dispersal) or winter sites, while adults maintain site fidelity to both breeding and winter locations (Gunnarsson et al., 2005, 2006; Gill et al., 2013). In general, fidelity to natal sites among animals - both migratory and sedentary - carries costs as well as benefits and most juvenile individuals must disperse away from their natal sites for their first breeding attempt (Winkler, 2005; Studds, Kyser \& Marra, 2008). Yet, most individuals disperse short distances (Hosner \& Winkler, 2007; Nathan et $a l ., 2012)$, and the adaptive value of preference for natal habitats, if not specific natal sites, bolsters philopatric tendencies (Davis \& Stamps, 2004; Stamps, Krishnan \& Reid, 2005) and likely contributes to selection for round-trip migrations. Thus, the existence of natal dispersal in migratory birds should not be interpreted as evidence against the profound influence of selection for breeding-site fidelity later in life on structuring the evolution of migratory and biogeographic patterns, even when such dispersal facilitates range expansions or shifts.

Of course, not all migratory birds always exhibit breeding-site fidelity from one year to the next. Variation exists in breeding-site fidelity within and across species that we are only beginning to understand due to the difficulty of detecting and measuring dispersal within species’ normal ranges (Rushing et al., 2015; Kempenaers \& Valcu, 2017; Boyle, 2018; Williams \& Boyle, 2018). At larger spatial scales, long-distance 'jump’ dispersal of adults has sometimes led to dramatic (i.e. intercontinental) range expansion events (de Queiroz, 2014). And, occasionally, a migratory population of birds does not come back to the original breeding grounds but rather begins breeding on its wintering grounds. This has been observed directly 
over the course of just a few generations (Winkler et al., 2017), and there is phylogenetic evidence that such migratory 'drop-offs' may have occurred regularly across macroevolutionary time scales (Kondo et al., 2008; Winger, Lovette \& Winkler, 2012; Rolland et al., 2014). But these exceptions prove the rule, by highlighting that for the vast majority of the time, natural selection favours individuals that not only migrate away from their breeding grounds when seasonal conditions deteriorate, but also return again the next season to the same breeding regions and often the same specific site where they raised young the year before.

\section{RECONCILING SEASONAL MIGRATION AND GEOGRAPHIC RANGE EVOLUTION}

We have argued that dispersal, not migration, is the mechanism that leads to range expansion into seasonal areas (Salewski \& Bruderer, 2007). We have also proposed that breeding-site fidelity, not dispersal to new breeding sites, is ultimately the driver of migration, and consequently that seasonal migration principally serves the adaptive function of maintaining familiar breeding territories in seasonal environments. Below, we explore how this perspective contributes to an understanding of the evolution of geographic range as well as biogeographic and macroecological patterns in lineages containing migratory species. 


\section{(1) Migration evolves similarly regardless of biogeographic origin}

By distinguishing dispersal from migration, it becomes clear that the biogeographic origin of a lineage need not be the same as the geographic region where migration evolved (Salewski \& Bruderer, 2007; Bruderer \& Salewski, 2008). For example, a sedentary tropical species may expand its range into more temperate areas through gradual dispersal, and in so doing, selection may cause the population to become migratory in the portions of its range that are more seasonal (Fig. 1). In this way, latitudinal migration may evolve in a tropical lineage as it expands its range poleward. That is, migration and geographic range evolve reciprocally, such that a lineage will not persist in regions with high seasonality unless it evolves migration (or an alternative adaptation for seasonality; Fig. 1), and only lineages exposed to pronounced seasonality will evolve latitudinal migrations (Gómez et al., 2016). Shorter-distance or facultative migrations, such as altitudinal migration (Boyle, 2011, 2017; Hsiung et al., 2018), may similarly evolve anywhere there are seasonal selection pressures that confer a fitness advantage to migration, including tropical areas with seasonality in climate and resources. In addition to a sedentary or partially migratory population becoming more migratory by expanding geographically into a more seasonal region, migration may also evolve as environments become more seasonal through time (Fig. 1). Just as populations undergoing range expansion into more seasonal areas will only persist if they adapt to increased seasonality, populations will only persist in situ if they adapt to temporal increases in seasonality (Fig. 1; Bruderer \& Salewski, 2008; Louchart, 2008; Winger et al., 2014). 
Because the selection pressures that drive the evolution of migration as populations expand their ranges across space are the same as those that drive the evolution of migration as seasonality changes through time, migration evolves through the same mechanisms regardless of the biogeographic origin of the lineage (Bruderer \& Salewski, 2008). For example, Louchart (2008) suggested that the contraction of tropical habitats to low latitudes during the Oligocene and Miocene caused the evolution of migratory behaviour in some lineages through the movement of winter ranges towards the equator and persistence of breeding ranges at high latitudes. This premise was supported by a phylogenetic reconstruction of breeding and winter ranges in a large clade of New World migratory birds, the Emberizoidea, which likely evolved migration through shifts of winter ranges to tropical latitudes from ancestral ranges in North America (Winger et al., 2014). Also found in North America are highly migratory birds of tropical origin, such as Tyrant Flycatchers (Tyrannidae), which trace their biogeographic origins to South America but have similar migratory patterns as many Emberizoids. However, that the ancestors of some migrants were found in the tropics does not necessitate invoking tropical home theories for the evolution of migration (e.g. Outlaw et al., 2003; Licona-Vera \& Ornelas, 2017; O'Connor et al., 2018). Rather, the ancestors of Neotropical migratory tyrannids and other birds of tropical origin likely evolved migration in tandem with gradual range expansion (via dispersal, not migration) into the more-seasonal areas of North America. Alternatively, some tropical species may have expanded their ranges into North America prior to the increases in seasonality in the Miocene, and only those that evolved migration in situ, like Emberizoidea, persisted. 
Although distinguishing these two historical biogeographic scenarios may not be possible in all cases, the selective forces acting on birds of high-latitude origin to migrate are likely the same as those that acted on birds of tropical origin that have colonized high latitudes (Bruderer \& Salewski, 2008): escape from unfavourable seasonal conditions, coupled with selection for breeding-site fidelity, as an adaptive strategy for persistence in a seasonal environment.

\section{(2) Dispersal, tropical niche conservatism and the colonization of seasonal environments}

Seasonality is an environmental filter for persistence in the temperate zone (Schluter, 2016), and the evolution of migration is similar to other adaptations (such as freeze tolerance in plants or hibernation in mammals) in allowing certain lineages, but not others, to colonize or persist at high latitudes. The pervasiveness of migration as an adaptation to seasonality across the avian tree of life relative to other adaptive strategies means that understanding global patterns of avian biogeography is not possible without an understanding of how and why migration evolves. However, whereas other adaptations to high-latitude life such as freeze tolerance or hibernation result in a broadening of climatic niches, the use of migration as a persistence strategy results in relative conservation of the thermal niche throughout the year because migrants escape the harshest climates (Laube, Graham \& Böhning-Gaese, 2015; Gómez et al., 2016; Eyres et al., 2017; Somveille, Manica \& Rodrigues, 2018a; Zurell et al., 2018). Consequently, seasonal migration has facilitated the colonization of several avian lineages of likely tropical origin in the temperate zone (such as Tyrannidae) as well as the persistence of high-latitude lineages as global 
temperatures have cooled over time, such as Parulidae (Winger et al., 2012, 2014), without necessitating the dramatic expansion of thermal tolerances required for adaptation to year-round temperate conditions.

In other avian lineages that have not colonized highly seasonal latitudes, the lack of a migratory response to seasonality may contribute to restricted tropical distributions. For example, some large avian lineages, such as the antbirds (Thamnophilidae and Formicariidae), are fully tropical and almost exclusively sedentary, despite high variation among species in elevational distribution and ecology within the tropics (Krabbe \& Schulenberg, 2003; Zimmer \& Isler, 2003). Such restricted latitudinal distributions are typically explained by greater niche conservatism relative to temperate species, which is a product of numerous factors including dispersal ability and physiological adaptation (Janzen, 1967; Wiens \& Donoghue, 2004; Smith et al., 2012). But given that seasonal migration, not cold tolerance, is the most widespread adaption to high seasonality in birds, we must consider the possibility that antbirds have failed to colonize temperate latitudes not only due to low vagility (e.g. Moore et al., 2008), propensity for invading new habitats or adapting physiologically to cold, but also due to a concomitant failure to evolve migration at the more seasonal peripheries of their ranges. That is, the lack of a migratory response to seasonality in some taxa may result in low survival and fitness of dispersers at the edge of the range and dampen the opportunity for further dispersal and range expansion into seasonal areas. Only two antbird species are thought to make regular seasonal movements, with both of these species migrating locally at the southernmost edges of their ranges in northern 
Argentina in austral winter (Zimmer \& Isler, 2003). This suggests that a migratory response to seasonality is not impossible in this speciose group, but highly unusual, and may contribute to the restriction of geographic ranges to low latitudes.

Our suggestion that the absence of a migratory response could restrict range expansion highlights the complex relationship between migration and dispersal. Because the evolution of migration via range expansion into a seasonal environment must first involve dispersal into a new environment, species with traits conferring higher dispersal ability or propensity may be more likely to evolve seasonal migration by virtue of greater exposure to selective pressures to migrate. Additionally, there may be a correlation between traits that mediate dispersal into new environments and those that enable an escape response to seasonally deteriorating conditions, such as vagility (Salewski \& Bruderer, 2007). That is, species that evolve migration may be those that not only are more likely to disperse, including into seasonal environments, but also are most likely to use escape as a persistence strategy when seasonal conditions become inadequate. Therefore, the traits identified as 'evolutionary precursors' (Levey \& Stiles, 1992) to migration in tropical birds, such as use of open or edge habitats (e.g. Chesser \& Levey, 1998; Outlaw \& Voelker, 2006; Boyle \& Conway, 2007; Bell, 2011), are not necessarily unrelated to the evolution of migration. Rather, any relationship between, for example, habitat occupancy and migratory versus sedentary behaviour is likely mediated by the intermediate influence of habitat on the propensity to disperse into seasonal environments where selection pressures to evolve migration are greater. Yet, the degree to which seasonal migration promotes versus restricts 
dispersal behaviour at different spatial scales, and the influence of this relationship on range expansion, is poorly understood and requires further research (Böhning-Gaese, GonzálezGuzmán \& Brown, 1998; Bensch, 1999; Hansson et al., 2002; Winkler, 2005; Henningsson \& Alerstam, 2008; Toews, 2017)

\section{(3) The evolution and persistence of disjunct geographic ranges in long-distance migrants}

Although many fascinating details of intraspecific variation in short-distance migratory behaviour demand investigation (Boyle, 2008; Boyle et al., 2010; Chapman et al., 2011; Zúñiga et al., 2017), it is not difficult to understand the adaptive value of short-distance migration in general terms. For example, the migration of the White-throated Sparrow (Zonotrichia albicollis) can be understood as a response to inadequate resources in most of the breeding range during the winter, with a fitness advantage conferred to individuals that travel a short distance south (Fig.

2). By contrast, in long-distance migratory species, most fundamental aspects of ecology and biogeography remain truly enigmatic. Why does the Bristle-thighed Curlew (Numenius tahitiensis) breed only in tundra on the north slope of Alaska and winter only on beaches in the south Pacific (Marks et al., 2002)? Why do Blackpoll Warblers, which prefer stunted boreal taiga for breeding, undergo a phenomenally long and arduous migration over the Atlantic Ocean to their wintering areas in lowland Amazonia and forego breeding or wintering in every habitat in between (Fig. 2; Deluca et al., 2015)? Although it is clear that migratory species are, as a general pattern, tracking resources during their migrations (Eyres et al., 2017; Somveille et al., 
2018a; Zurell et al., 2018), the details of species' distributions remain difficult to understand: ecological idiosyncrasies and bizarre range disjunctions are the norm rather than the exception among long-distance migratory species.

Conceptualizing migration as a strategy for persistence in a seasonal environment driven by fidelity to breeding sites removes the mystery, if not the idiosyncrasy, of disjunct breeding and winter ranges in long-distance migratory species. Present-day winter ranges are simply the locations that have allowed individuals to maintain reproductive success on the breeding grounds. Severe disjunctions between breeding and winter ranges in long-distance migratory species have likely evolved gradually and reflect the dynamic and stochastic nature of range evolution. For example, as breeding ranges at high latitudes contracted, expanded and shifted during cycles of glaciation (Milá, Smith \& Wayne, 2006), so too have winter ranges and migratory routes - and field studies of small-scale range shifts over recent decades, such as in Icelandic Black-tailed Godwits, suggest the mechanism for both breeding- and winter-range shifts is natal dispersal (i.e. population recruitment; Gunnarsson et al., 2005, 2006). Over millennia, however, winter ranges in more climatically stable lower latitudes may not have shifted as much as high-latitude breeding ranges as a consequence of glaciation cycles, potentially resulting in the poleward shifting of breeding ranges while the location of the winter range has remained relatively more static (Ruegg \& Smith, 2002; Milá et al., 2006; Zink \& Gardner, 2017). Consequently, the perplexingly long-distance migratory journeys that so capture our imagination, such as the Bristle-thighed Curlew or the Blackpoll Warbler, reflect the 
'whatever works' nature of migration as a persistence strategy: because migratory behaviour is highly heritable either genetically or culturally, winter ranges and extreme migratory routes may persist through generations (and perhaps millennia) as long as they confer sufficient over-winter fitness to maintain reproductive success the following breeding season (Conklin et al., 2017). The paired association of breeding and winter ranges among migratory populations are further idiosyncratic as a consequence of phylogenetic diversification. Assuming a non-sympatric speciation model, speciation in migratory lineages necessarily involves cladogenic inheritance of only a portion of the breeding range (Ree et al., 2005). Depending on patterns of migratory connectivity (see Section VI), cladogenesis likely involves inheritance of only a portion of the wintering range as well, resulting in daughter species with idiosyncratically divided breeding and winter ranges (Winker \& Pruett, 2006; Ruegg, 2008; Winker, 2010; Winger et al., 2012, 2014).

Our suggestion that historical stochasticity underlies much of the idiosyncrasy of longdistance migration does not imply that ecological adaptations to specific winter areas by longdistance migrants are unimportant. On the contrary, full-annual-cycle studies of migratory populations reveal that, within species, the nuances of winter ecology are highly consequential for reproductive success in subsequent breeding seasons (Norris et al., 2004; Reudink et al., 2009; Marra et al., 2015; Rushing et al., 2015). Collectively, these studies suggest that expansion of or changes to winter ranges in long-distance migrants is not simply a matter of achieving overwinter survival or improving winter condition of migratory individuals, which could lead to high lability of the winter range. Rather, for geographic modifications of non-breeding ranges to 
persist, changes in winter distributions or ecology must translate to higher reproductive success than conspecifics (Bearhop et al., 2005) or new migratory strategies will not proliferate in a population. The intricate relationship between winter ecology and breeding success may therefore confer a measure of temporal stability to migratory patterns in some species, resulting in the persistence of long-distance migrations even when closer suitable winter ranges or more efficient migratory routes (e.g. Somveille et al., 2018a) are theoretically available.

However, stability and persistence of migration is not considered the norm. Rather, the dominant viewpoint on the evolution of migration is one of high lability and plasticity. Because migration has been shown to evolve rapidly in some species, it is often stated that migratory behaviour is universally labile (e.g. Helbig, 2003; Pulido, 2007). Most evidence for rapid changes in migration come from a small number of species of facultative or partial migrants, most prominently the Eurasian Blackcap (Sylvia atricapilla), a species which exhibits substantial diversity in migratory behaviour and has modified its wintering range in recent decades (Berthold et al., 1992; Pulido \& Berthold, 2010). The variability in migration displayed by the Eurasian Blackcap provides an excellent system for researching many aspects of the evolution of migration (Pulido, 2007), but how conclusions drawn from research on partial or facultative migrants should be applied to migratory species more broadly requires critical thought (Piersma et al., 2005; Piersma, 2011). In particular, it is important to recognize that the role of plasticity in evolution is not only a story of the maintenance of plasticity and constant fluidity in trait evolution, it is also frequently a story of the loss of plasticity due to genetic assimilation (Price, 
Qvarnstrom \& Irwin, 2003; West-Eberhard, 2003; Pigliucci, Murren \& Schlichting, 2006).

During genetic assimilation, changes in the environment expose plastic phenotypes to strong selection, potentially towards new adaptive peaks. If shifts in environmental conditions are persistent throughout generations, plasticity may be lost and phenotype will no longer vary according to previous reaction norms. That is, selection for a particular extreme of an initially plastic phenotype can result in the loss of plasticity.

Canalization of migratory traits (i.e. loss of plasticity) likely plays an underappreciated role in the evolution of migratory patterns (Winker, 2010; Pulido, 2011). In particular, the idiosyncratic ranges and routes of obligate long-distance migratory species may be evidence of canalization of plasticity in migratory behaviour in conjunction with stochastic biogeographic changes. Therefore, the fluidity of migratory behaviour in some species is not evidence that migration in all lineages is subject to rapid change. Rather, it is evidence that migration is a behaviourally plastic trait - and behaviourally plastic traits may be subject to genetic assimilation and the loss of plasticity (Ehrenreich \& Pfennig, 2016). Thus, in some species, obligate migratory behaviour may have persisted even as geographic ranges shifted (for example, during glacial cycles, which have recently been regarded as implicitly necessitating profound shifts in migratory behaviour; Zink \& Gardner, 2017). In other species in which plasticity for migration persists or is itself adaptive, subtle environmental changes may lead to rapid changes in a population's migratory behaviour due to sensitivity to variation in reaction norms; such plasticity likely accounts for changes to the migratory behaviour and geographic range observed 
in some species over years or decades (e.g. Able \& Belthoff, 1998). Across species, variability in the maintenance of plasticity for migratory traits versus their past canalization and loss of plasticity may underlie much of the fascinating idiosyncrasy and diversity observed in species' migratory routes and ranges and will likely influence their adaptive responses to rapid anthropogenic climate change (Gilroy et al., 2016; Senner, Stager, \& Cheviron, 2017; Williams et al., 2017).

\section{SYNOPSIS: A LONG WINTER FOR THE RED QUEEN}

The Lewis Carroll quote that inspired Van Valen's (1973) Red Queen hypothesis for persistence in a changing environment ("it takes all the running you can do, to keep in the same place") has illuminated numerous evolutionary phenomena related to the ever-shifting nature of adaptation. If readers will indulge a more literal interpretation of the metaphor than intended by Van Valen, the Red Queen's axiom also provides a succinct summary of our synthesis of the evolution of seasonal migration. Organisms increase their reproductive success through breeding-site fidelity, that is, staying in or near to the same place. In environments in which resources seasonally become scarce and environments harsh, organisms must evolve adaptations to these cyclical environmental changes to achieve the reproductive advantages associated with site fidelity. Some organisms evolve physiological, neurological or behavioural adaptations that keep them near their breeding areas through the harshest times of year; but in many bird species, 
migrating has proven the most successful solution. It takes all the flying you can do to keep in the same place.

A central question for understanding the evolution of migration, then, is why is there such tremendous variation in migratory journeys even among species that breed in similar locations? Migratory distance varies markedly among closely related species, and also among individuals of some populations, making it difficult to understand why specific migratory strategies or routes have evolved. Hermit Thrushes (Catharus guttatus), Swainson's Thrushes (C. ustulatus) and Veeries (C. fuscescens), three closely related species, frequently breed in the same hectare of eastern North American temperate forest but winter in drastically different regions - one in the southern USA, one in the Andes, and the other in Amazonia (Outlaw et al., 2003). We know a great deal about the natural history of these three species and have learned much about how they accomplish their migrations (e.g. Bowlin \& Wikelski, 2008; Deppe et al., 2015; Gómez et al., 2017), but we have few answers as to why the migratory journeys and strategies of these species differ from one another, other than to dismiss the question outright by acknowledging that all geographic ranges are idiosyncratic and ephemeral reflections of numerous biotic, abiotic and historical factors.

Over the last two decades, many studies have begun leveraging technological advantages to study the relationship between breeding and winter locations within migratory species (Rubenstein et al., 2002; Webster et al., 2002; Cohen et al., 2017). This is the field of migratory connectivity, which seeks to describe how the location where an individual breeds (in the context 
of the full breeding range of its species) predicts the spatial location of its wintering location (within the winter range of its species). Collectively, these studies have revealed much idiosyncrasy in connectivity among species (Cohen et al., 2017). For example, some species exhibit parallel, and thus somewhat predictable connectivity, with eastern breeders wintering east of western breeders throughout their ranges (Kramer et al., 2018), whereas other species have more surprising crosswise migrations between breeding and wintering locations (Witynski \& Bonter, 2018).

Given such idiosyncrasy in migratory connectivity within species, it is natural to focus on individual-level variation in migratory behaviour, and indeed this variation has important implications for the ecology and conservation of migratory birds (Cooper et al., 2018; Kramer et al., 2018). However, the geographic ranges of species are emergent properties of the movements and territories of individuals. As the connectivity of more species is described, the synthesis of this information across species will provide a yet-untapped potential to understand the evolution of broader biogeographic patterns. For example, to what extent do migratory species track certain habitat requirements, as opposed to climatic conditions, making distributions ecologically deterministic (Thorup et al., 2017)? How does competition among closely related species vary throughout the annual cycle and dictate seasonal patterns of sympatry versus segregation (Gross \& Price, 2000)? By continuing to gather natural-history information on species' migratory behaviour and contextualizing this variation as alternative manifestations of an adaptation that enables species to persist in fluctuating and ever-changing environments, migratory species will 
provide a powerful lens into the factors that control local adaptation and geographic range evolution as well as species' ability to persist in our present rapidly changing world.

\section{CONCLUSIONS}

(1) Understanding the evolution of migration and its consequences for geographic range dynamics has been constrained by the assumption that migration arose as a means of colonizing new breeding sites in regions that were thought to confer higher reproductive success.

(2) We argue that migration has evolved following regular (i.e. short-distance) breeding dispersal into seasonal areas or following increases in seasonality within existing ranges, as an adaption for persistence analogous to other strategies for coping with fluctuating environments.

(3) We propose that the reproductive benefit of maintaining fidelity to breeding sites has selected for regular, cyclical migrations in many species as opposed to nomadic behaviour or irregular movements. That is, returning to familiar locations for breeding, as opposed to exploring new sites for breeding, underlies the evolution of seasonal migration as a strategy to persist in seasonal environments. This hypothesis is supported by decades of research on the breeding biology of migratory birds, as well as theory suggesting that species prefer their natal habitats when undergoing dispersal. The adaptive value of migrating long distances to maintain site fidelity can be conceptualized as a biogeographic Red Queen metaphor.

(4) Regarding seasonal migration as an adaptation that facilitates persistence in seasonal environments allows the decoupling of the biogeographic origins of migratory lineages and the 
mechanism by which migration evolves. Thus, lineages may be of broadly different biogeographic origins (e.g. Southern versus Northern Hemisphere) but nevertheless evolve migration in seasonal environments as a consequence of the same selection pressures to cope with seasonality. This decoupling of history and mechanism will lead to a more productive analysis of geographic range evolution in lineages containing migratory species and the mechanisms by which disjunct wintering and breeding ranges arise and are maintained through time.

(5) Our conceptualization of the evolution of migration places new emphasis on previously under-appreciated avenues of research. In particular, understanding the evolutionary trade-offs of adopting migration as opposed to alternative coping strategies for seasonal resource limitation and harsh environmental conditions is an underexplored area of research in organismal biology. (6) Geographic ranges are fluid and complex phenomena, even in sessile species, and ranges are sometimes thought to be even more mutable in migratory species due to the rapidity with which migratory behaviour can change. However, the role of genetic assimilation (i.e. loss of plasticity) in the evolution of migratory patterns has been under-appreciated and may help explain the idiosyncratic migratory routes and distributions observed in many species.

(7) An improved understanding and contextualization of the ecological and historical linkages between breeding and non-breeding locations within migratory species will provide a promising framework from which to illuminate the forces that dictate where and when species exist across the earth. 


\section{ACKNOWLEDGMENTS}

For helpful comments on the manuscript we thank Eric Gulson-Castillo, Benjamin Van Doren, and two anonymous reviewers.

\section{REFERENCES}

ABLE, K. \& BELTHOFF, J. (1998). Rapid 'evolution' of migratory behaviour in the introduced house finch of eastern North America. Proceedings of the Royal Society B: Biological Sciences 265, 2063-2071.

Alerstam, T. \& BÄCKMAn, J. (2018). Ecology of animal migration. Current Biology 28, R968R972. Elsevier.

Alerstam, T., Hedenstrom, A. \& AKesson, S. (2003). Long-distance migration: evolution and determinants. Oikos 103, 247-260.

Altizer, S., BARTEL, R. \& HAN, B.A. (2011). Animal migration and infectious disease risk. Science 331, 296-302.

Bearhop, S., Fiedler, W., Furness, R., Votier, S., Waldron, S., Newton, J., Bowen, G., BERTHOLD, P. \& FARNSWORTH, K. (2005). Assortative mating as a mechanism for rapid evolution of a migratory divide. Science 310, 502-504.

BELL, C.P. (2000). Process in the evolution of bird migration and pattern in avian ecogeography. Journal of Avian Biology 31, 258-265.

BELL, C.P. (2005). The origin and development of bird migration: comments on Rappole and Jones, and an alternative evolutionary model. Ardea 93, 115-123.

BELL, C.P. (2011). Resource buffering and the evolution of bird migration. Evolutionary Ecology 25, 91-106.

BENSCH, S. (1999). Is the range size of migratory birds constrained by their migratory program? Journal of Biogeography 26, 1225-1235.

Bensch, S., Hasselquist, D., Nielsen, B. \& Hansson, B. (1998). Higher fitness for philopatric than for immigrant males in a semi-isolated population of Great Reed Warblers. Evolution 52, 877-883.

BERTHOLD, P. (1999). A comprehensive theory for the evolution, control and adaptability of avian migration. Ostrich 70, 1-11.

Berthold, P., Helbig, A.J., Mohr, G. \& Querner, U. (1992). Rapid microevolution of migratory behaviour in a wild bird species. Nature 360, 668-670.

BisSON, I.-A., SAFI, K. \& HolLAND, R.A. (2009). Evidence for repeated independent evolution of migration in the largest family of bats. PLoS ONE 4, e 7504.

This article is protected by copyright. All rights reserved. 
Blackburn, E. \& CResswell, W. (2016). High winter site fidelity in a long-distance migrant: implications for wintering ecology and survival estimates. Journal of Ornithology 157, 93108.

BÖHNing-GAESE, K., GonZÁLEZ-GuZMÁn, L.I. \& BROwn, J.H. (1998). Constraints on dispersal and the evolution of the avifauna of the Northern Hemisphere. Evolutionary Ecology 12, 767-783.

Bonte, D., Van Dyck, H., Bullock, J.M., Coulon, A., Delgado, M., GibBs, M., Lehouck, V., Matthysen, E., Mustin, K., SaAstamoinen, M., Schtickzelle, N., Stevens, V.M., VAndewoestijne, S., BAguette, M., BARton, K., ET AL. (2012). Costs of dispersal. Biological Reviews 87, 290-312.

BOWLIN, M.S. \& WIKELSKI, M. (2008). Pointed wings, low wingloading and calm air reduce migratory flight costs in songbirds. PLoS ONE 3, e2154.

BOYLE, W.A. (2008). Partial migration in birds: Tests of three hypotheses in a tropical lekking frugivore. Journal of Animal Ecology 77, 1122-1128.

BOYLE, W.A. (2011). Short-distance partial migration of Neotropical birds: A community-level test of the foraging limitation hypothesis. Oikos 120, 1803-1816.

BOYLE, W.A. (2017). Altitudinal bird migration in North America. The Auk 134, 443-465.

Boyle, W.A. (2018). Movement ecology. In Ornithology: Foundation, Critique, and Application (eds M. Morrison, A.D. Rodewald, G. Voelker, M. Colon \& J. Prather), p. Johns Hopkins University Press, Baltimore, MD.

Boyle, W.A. \& CONWAY, C.J. (2007) Why migrate? A test of the evolutionary precursor hypothesis. The American Naturalist 169, 344-359.

Boyle, W.A., Conway, C.J. \& BROnStein, J.L. (2010). Why do some, but not all, tropical birds migrate? A comparative study of diet breadth and fruit preference. Evolutionary Ecology 25, 219-236.

BRIGHAM, R.M. (1992). Daily torpor in a free-ranging goatsuckers, the common poorwill (Phalaenoptilus nuttallii). Physiological Zoology 65, 457-472.

BRUDERER, B. \& SALEWSKI, V. (2008). Evolution of bird migration in a biogeographical context. Journal of Biogeography 35, 1951-1959.

Chapman, B.B., Brönmark, C., Nilsson, J.Å. \& HAnsson, L.A. (2011). The ecology and evolution of partial migration. Oikos 120, 1764-1775.

Charmantier, A. \& GienapP, P. (2014). Climate change and timing of avian breeding and migration: Evolutionary versus plastic changes. Evolutionary Applications 7, 15-28.

Chesser, R. \& LEVEY, D. (1998). Austral migrants and the evolution of migration in new world birds: Diet, habitat, and migration revisited. American Naturalist 152, 311-319.

Cohen, E.B., Hostetler, J.A., Hallworth, M.T., Rushing, C.S., Sillett, T.S. \& Marra, P.P. (2017). Quantifying the strength of migratory connectivity. Methods in Ecology and Evolution 2018, 513-524.

Conklin, J.R., Senner, N.R., Battley, P.F. \& Piersma, T. (2017). Extreme migration and the individual quality spectrum. Journal of Avian Biology 48, 19-36.

This article is protected by copyright. All rights reserved. 
Cooper, N.W., Ewert, D.N., Hall, K.R., Rockwell, S.M., Currie, D., Wunderle, J.M. \& JENNIFER, D. (2018). Resighting data reveal weak connectivity from wintering to breeding grounds in a range-restricted and endangered long-distance migratory passerine. Avian Conservation and Ecology 13, 9.

Cote, J., Bestion, E., Jacob, S., Travis, J., Legrand, D. \& Baguette, M. (2017). Evolution of dispersal strategies and dispersal syndromes in fragmented landscapes. Ecography 40, 5673.

Cox, G. (1985). The evolution of avian migration systems between the temperate and tropical regions of the New World. American Naturalist 126, 451-474.

Cox, G.W. (1968). The role of competition in the evolution of migration. Evolution 22, 180-192.

Cresswell, K., Satterthwaite, W. \& Sword, G. (2011). Understanding the evolution of migration through empirical examples. In Animal Migration: A Synthesis (eds E. MiLnERGulland, J. FryXell \& A. SinClaIR), pp. 7-16. Oxford University Press, Oxford.

CResswell, W. (2014). Migratory connectivity of Palaearctic - African migratory birds and their responses to environmental change: the serial residency hypothesis. Ibis 156, 493-510.

DAVIS, J.M. \& STAMPS, J.A. (2004) The effect of natal experience on habitat preferences. Trends in Ecology and Evolution 19, 411-416.

Del Hoyo, J., Elliott, A., Sargatal, J., Christie, D.A. \& Kirwan, G. (eds.) (2018). Handbook of the Birds of the World. Alive. Lynx Edicions, Barcelona.

Deluca, W. V, Woodworth, B.K., Rimmer, C.C., Marra, P.P., TaYlor, P.D., McFarland, K.P., MACKENZIE, S.A. \& NorRIS, D.R. (2015). Transoceanic migration by a 12 g songbird. Biology Letters 11, 20141045.

Deppe, J.L., Ward, M.P., Bolus, R.T., Diehl, R.H., Celis-Murillo, A., ZenZal, T.J., Moore, F.R., Benson, T.J., SMolinsky, J.A., Schofield, L.N., Enstrom, D.A., PAXTON, E.H., Bohrer, G., BEVERoth, T.A., RAIM, A., ET AL. (2015). Fat, weather, and date affect migratory songbirds' departure decisions, routes, and time it takes to cross the Gulf of Mexico. Proceedings of the National Academy of Sciences 112, E6331-E6338.

DE QueIROZ, A. (2014). The Monkey's Voyage: How improbable journeys shaped the history of life. Basic Books, New York.

DingLE, H. (2006). Animal migration: Is there a common migratory syndrome? Journal of Ornithology 147, 212-220.

Dokter, A.M., Farnsworth, A., Fink, D., Ruiz-Gutierrez, V., HochachKa, W.M., LA Sorte, F.A., Robinson, O.J., RosenberG, K. V. \& Kelling, S. (2018). Seasonal abundance and survival of North America's migratory avifauna determined by weather radar. Nature Ecology \& Evolution. In press.

Doligez, B. \& PÄRT, T. (2008). Estimating fitness consequences of dispersal: A road to 'knowwhere'? Non-random dispersal and the underestimation of dispersers' fitness. Journal of Animal Ecology 77, 1199-1211.

Douglas, T.K., CoOper, C.E. \& Withers, P.C. (2017). Avian torpor or alternative thermoregulatory strategies for overwintering? The Journal of Experimental Biology 220,

This article is protected by copyright. All rights reserved. 
$1341-1349$.

Ehrenreich, I.M. \& Pfennig, D.W. (2016). Genetic assimilation: A review of its potential proximate causes and evolutionary consequences. Annals of Botany 117, 769-779.

Eyres, A., BÖHNING-GAESE, K. \& FRITZ, S.A. (2017). Quantification of climatic niches in birds: Adding the temporal dimension. Journal of Avian Biology 48, 1517-1531.

Fristoe, T.S., IwANIUK, A.N. \& Botero, C.A. (2017). Big brains stabilize populations and facilitate colonization of variable habitats in birds. Nature Ecology and Evolution 1, 17061715. Springer US.

Fudickar, A.M., Peterson, M.P., Greives, T.J., Atwell, J.W., Bridge, E.S. \& Ketterson, E.D. (2016). Differential gene expression in seasonal sympatry: mechanisms involved in diverging life histories. Biology Letters 12, 20160069.

GauthreauX, S. (ed) (1980). Animal Migration, Orientation, and Navigation. Academic Press, New York.

GaUthreauX, S. (1982). The ecology and evolution of avian migration systems. In Avian Biology (eds D. FARner, K. PARKES \& J. KING), pp. 93-168, 6th edition. Academic Press, New York, NY.

GEISER, F. (2004). Metabolicrate and body temperature reduction during hibernation and daily torpor. Annual Review of Physiology 66, 239-274.

GILL, F.B. (2007). Ornithology. W. H. Freeman and Company, New York, NY.

Gill, J.A., Alves, J.A., Sutherland, W.J., Appleton, G.F., Potts, P.M. \& Gunnarsson, T.G. (2013). Why is timing of bird migration advancing when individuals are not? Proceedings of the Royal Society B: Biological Sciences 281, 20132161.

Gilroy, J.J., Gill, J.A., Butchart, S.H.M., Jones, V.R. \& Franco, A.M.A. (2016) Migratory diversity predicts population declines in birds. Ecology Letters 19, 308-317.

Gómez, C., BAYly, N.J., RyAn, D.N., Mackenzie, S.A., KenNeTh, V., TAYLOR, P.D., HobSON, K.A. \& CADENA, C.D. (2017). Fuel loads acquired at a stopover site influence the pace of intercontinental migration in a boreal songbird. Scientific Reports 7, 1-11.

Gómez, C., Larsen, T., Popp, B., Hobson, K.A., Carlos, \& CadenA, D. (2018). Assessing seasonal changes in animal diets with stable- isotope analysis of amino acids: a migratory boreal songbird switches diet over its annual cycle. Oecologia 187, 1-13.

Gómez, C., Tenorio, E.A., Montoya, P. \& CADENA, C.D. (2016). Niche-tracking migrants and niche- switching residents: evolution of climatic niches in New World warblers (Parulidae). Proceedings of the Royal Society B: Biological Sciences 283, 20152458.

Greenwood, P.J. \& HARVEY, P.H. (1982). The natal and breeding dispersal of birds. Annual Review of Ecology and Systematics 13, 1-21.

Gross, S.J. \& PRICE, T.D. (2000). Determinants of the northern and southern range limits of a warbler. Darwin 27, 869-878.

Gunnarsson, T.G., Gill, J.A., Atkinson, P.W., Gélinaud, G., Potts, P.M., Croger, R.E., Gudmundsson, G.A., Appleton, G.F. \& Sutherland, W.J. (2006). Population-scale drivers of individual arrival times in migratory birds. Journal of Animal Ecology 75, 1119- 
1127.

Gunnarsson, T.G., Gill, J.A., Newton, J., Potts, P.M. \& Sutherland, W.J. (2005). Seasonal matching of habitat quality and fitness in a migratory bird. Proceedings of the Royal Society B: Biological Sciences 272, 2319-2323.

GuTTAL, V. \& CouZIN, I.D. (2010). Social interactions, information use, and the evolution of collective migration. Proceedings of the National Academy of Sciences 107, 16172-16177.

Hansson, B., Bensch, S. \& HAsselquist, D. (2004). Lifetime fitness of short-and long-distance dispersing Great Reed Warblers. Evolution 58, 2546-2557.

Hansson, B., BensCh, S., Hasselquist, D. \& Nielsen, B. (2002). Restricted dispersal in a long-distance migrant bird with patchy distribution, the great reed warbler. Oecologia 130, 536-542.

HeERS, A.M. \& DiAL, K.P. (2015). Wings versus legs in the avian bauplan: Development and evolution of alternative locomotor strategies. Evolution 69, 305-320.

HeINRICH, B. (2003a). Overnighting of Golden-crowned Kinglets during winter. The Wilson Bulletin 115, 113-224.

HeINRICH, B. (2003b). Winter World. Harper Collins, New York, NY.

HelBIG, A. (2003) Evolution of bird migration: A phylogenetic and biogeographic perspective. In Avian Migration (eds P. Berthold, E. GWInNER \& E. SONNENSCHEIN), pp. 3-20. Springer-Verlag, Berlin.

Henningsson, S.S. \& Alerstam, T. (2008). Does migration promote or restrict circumpolar breeding ranges of arctic birds? Journal of Biogeography 35, 781-790.

Holmes, R.T. \& SHERRY, T.W. (1992). Site fidelity of migratory warblers in temperate breeding and neotropical wintering areas: implications for population dynamics, habitat selection, and conservation. In Ecology and conservation of Neotropical migrant landbirds (eds J. Hagan \& D. Johnston), pp. 563-578. Smithsonian Institution Press, Washington, D.C.

Holmes, R.T., Sherry, T.W. \& Reitsma, L. (1989). Population structure, territoriality and overwinter survival of two migrant warbler species in Jamaica. The Condor 91, 545-561.

Hoover, J.P. (2003). Decision rules for site fidelity in a migratory bird, the Prothonotary Warbler. Ecology 84, 416-430.

Horton, K.G., Van Doren, B.M., Stepanian, P.M., Farnsworth, A. \& Kelly, J.F. (2016). Seasonal differences in landbird migration strategies. The Auk 133, 761-769.

Hosner, P.A. \& WinkleR, D.W. (2007). Dispersal distances of Tree Swallows estimated from continent-wide and limited-area data. Journal of Field Ornithology 78, 290-297.

Hsiung, A.C., Boyle, W.A., CoOPer, R.J. \& ChAndler, R.B. (2018). Altitudinal migration: ecological drivers, knowledge gaps, and conservation implications. Biological Reviews.

JAEGER, E. (1948). Does the Poor-will 'Hibernate'? The Condor 50, 45-46.

JAEGER, E. (1949). Further observations on the hibernation of the poor-will. The Condor 51, $105-109$.

JAhn, A., LeVEY, D. \& SMith, K. (2004). Reflections across hemispheres: A system-wide approach to new world bird migration. Auk 121, 1005-1013.

This article is protected by copyright. All rights reserved. 
JANZEN, D. (1967). Why mountain passes are higher in the tropics. American Naturalist 101, 233-249.

JOSEPH, L., LESSA, E. \& CHRISTIDIS, L. (1999). Phylogeny and biogeography in the evolution of migration: shorebirds of the Charadrius complex. Journal of Biogeography 26, 329-342.

KeAst, A. \& MorTon, E. (eds) (1980). Migrant Birds in the Neotropics. Smithonian Institution, Washington, D.C.

Kempenaers, B. \& VAlcu, M. (2017). Breeding site sampling across the Arctic by individual males of a polygynous shorebird. Nature 541, 528-531.

KetTERSON, E.D. \& Nolan, V. (1982). The role of migration and winter mortality in the life history of a temperate-zone Migrant, the Dark-Eyed Junco, as determined from demographic analyses of winter populations. The Auk 99, 243-259.

KoKKo, H. (1999). Competition for early arrival in migratory birds. Journal of Animal Ecology 58, 940-950.

KOKKO, H. (2011). Directions in modelling partial migration: How adaptation can cause a population decline and why the rules of territory acquisition matter. Oikos 120, 1826-1837.

Kondo, B., Peters, J.L., Rosensteel, B.B. \& Omland, K.E. (2008). Coalescent analyses of multiple loci support a new route to speciation in birds. Evolution 62, 1182-1191.

KrabBe, N. \& SchUlenBERG, T.S. (2003). Family Formicariidae (Ground-Antbirds). In Handbook of the Birds of the World Volume 8 (eds J. DEL HoYo, A. ElliOT \& D. CHRISTIE), pp. 682-731. Lynx Edicions, Barcelona, Spain.

Kramer, G.R., Andersen, D.E., Buehler, D.A., Wood, P.B., Peterson, S.M., Lehman, J.A., Aldinger, K.R., Bulluck, L.P., Harding, S., Jones, J.A., Loegering, J.P., Smalling, C., VALLENDER, R. \& STREBY, H.M. (2018). Population trends in Vermivora warblers are linked to strong migratory connectivity. Proceedings of the National Academy of Sciences 115, E3192-E3200.

LACK, D. (1968). Bird migration and Natural Selection. Oikos 19, 1-9.

LAuBE, I., GraHAM, C.H. \& BÖHNING-GAESE, K. (2015). Niche availability in space and time: migration in Sylvia warblers. Journal of Biogeography 42, 1896-1906.

LEVEY, D. \& STILES, F. (1992). Evolutionary precursors of long-distance migration: Resource availability and movement patterns in neotropical landbirds. American Naturalist 140, 447476.

LEVEY, D.J. (1994). Why we should adopt a broader view of Neotropical migrants. The Auk 111, 233-236.

LICONA-VERA, Y. \& ORNELAS, J.F. (2017). The conquering of North America: dated phylogenetic and biogeographic inference of migratory behavior in bee hummingbirds. BMC Evolutionary Biology 17, 1-17. BMC Evolutionary Biology.

LOUCHART, A. (2008). Emergence of long distance bird migrations: a new model integrating global climate changes. Naturwissenschaften 95, 1109-1119.

LyMAn, S., Wills, J., MALAN, A. \& WANG, L. (1982). Hibernation and torpor in mammals and birds. Academic Press, New York, NY.

This article is protected by copyright. All rights reserved. 
Marks, J., TibBits, T., GiLl, R. \& McCAFFERY, J. (2002). Bristle-thighed Curlew (Numenius tahitiensis), version 2.0. In The Birds of North America (eds A. POOLE \& F. GILL), p. Cornell Lab of Ornithology, Ithaca, NY.

Marra, P., Cohen, E.B., Loss, S.R., RutTer, J.E. \& Tonra, C.M. (2015). A call for full annual cycle research in animal ecology. Biology Letters 11, 2015.0552.

Marra, P., Hobson, K. \& Holmes, R. (1998). Linking winter and summer events in a migratory bird by using stable-carbon isotopes. Science 282, 1884-1886.

MARTIN, T.E. (2004). Avian life-history evolution has an eminent past: does it have a bright future? The Auk 121, 289-301.

MARTIN, T.E. (2015). Age-related mortality explains life history strategies of tropical and temperate songbirds. Science 349, 966-970.

MARZlufF, J.M., HeINRICH, B. \& MARZlufF, C.S. (1996). Raven roosts are mobile information centres. Animal Behaviour 51, 89-103.

MAtThysen, E. (2005). Density-dependent dispersal in birds and mammals in birds and mammals. Ecography 28, 403-416.

MAYR, E. \& MEISE, W. (1930). Theoretisches zur geschichte des vogelzuges. Vogelzug 1, :149172.

McKechnie, A.E. \& Lovegrove, B.G. (2002). Avian facultative hypothermic responses: a review. The Condor 104, 705-724.

MilÁ, B., Smith, T. \& WAYNe, R. (2006). Postglacial population expansion drives the evolution of long-distance migration in a songbird. Evolution 60, 2403-2409.

Milner-Gulland, E., FryXell, J. \& Sinclair, A. (eds) (2011). Animal Migration: A synthesis. Oxford University Press, Oxford.

Moore, R.P., Robinson, W.D., LovetTe, I.J. \& Robinson, T.R. (2008). Experimental evidence for extreme dispersal limitation in tropical forest birds. Ecology letters 11, 960-968.

Nathan, R., Klein, E., Robledo-Arnuncio, J.J. \& Revilla, E. (2012). Dispersal kernels: review. In Dispersal Ecology and Evolution (eds J. Clobert, M. BAGUeTte, T.G. Benton \& J.M. BullOCK), pp. 186-210. Oxford University Press, Oxford.

Newton, I. (2010). The migration ecology of birds. Academic Press, London.

Norris, D.R., MARrA, P.P., KYSER, T.K., SHERry, T.W. \& RATClifFE, L.M. (2004). Tropical winter habitat limits reproductive success on the temperate breeding grounds in a migratory bird. Proceedings of the Royal Society B: Biological Sciences 271, 59-64.

O’Connor, E.A., Cornwallis, C.K., Hasselquist, D., Nilsson, J.A. \& Westerdahl, H. (2018). The evolution of immunity in relation to colonisation and migration. Nature Ecology \& Evolution 2, 841-849.

Outlaw, D., Voelker, G., Mila, B. \& Girman, D. (2003). Evolution of long-distance migration in and historical biogeography of Catharus thrushes: A molecular phylogenetic approach. Auk 120, 299-310.

Outlaw, D.C. \& VoelKer, G. (2006). Phylogenetic tests of hypotheses for the evolution of avian migration: a case study using the Motacillidae. The Auk 123, 455-466.

This article is protected by copyright. All rights reserved. 
PÄRT, T. (1995). The importance of local familiarity and search costs for age- and sex-biased philopatry in the collared flycatcher. Animal Behaviour 49, 1029-1038.

PAYNE, R.B. \& PAYNE, L.L. (1993). Breeding dispersal in Indigo Buntings: circumstances and consequences for breeding success and population structure. The Condor 95, 1-24.

PERRINS, C.M. (1970). The timing of birds' breeding seasons. Ibis 112, 242-255.

PIERSMA, T. (2011). Flyway evolution is too fast to be explained by the modern synthesis: proposals for an 'extended' evolutionary research agenda. Journal of Ornithology 152, 151159.

Piersma, T., Pérez-Tris, J., Mouritsen, H., Bauchinger, U. \& Bairlein, F. (2005). Is there a "migratory syndrome" common to all migrant birds? Annals of the New York Academy of Sciences 1046, 282-293.

Pigliucci, M., Murren, C.J. \& SChlichting, C.D. (2006). Phenotypic plasticity and evolution by genetic assimilation. The Journal of Experimental Biology 209, 2362-2367.

Pravosudov, V. V., SANFORD, K. \& HAHN, T.P. (2007). On the evolution of brain size in relation to migratory behaviour in birds. Animal Behaviour 73, 535-539.

Price, T., KirKPatrick, M. \& ARnOld, S.J. (1988). Directional selection and the evolution of breeding date in birds. Science 240, 798-799.

Price, T.D., QVARnstrom, A. \& IRWIN, D.E. (2003). The role of phenotypic plasticity in driving genetic evolution. Proceedings of the Royal Society B: Biological Sciences 270, 1433-1440.

Pulido, F. (2007). The genetics and evolution of avian migration. Bioscience 57, 165-174.

PULIDO, F. (2011). Evolutionary genetics of partial migration - the threshold model of migration revis(it)ed. Oikos 120, 1776-1783.

Pulido, F. \& BERTHOLD, P. (2010). Current selection for lower migratory activity will drive the evolution of residency in a migratory bird population. Proceedings of the National Academy of Sciences 107, 7341-7346.

RAPPOLE, J. (1995). The ecology of migrant birds: A Neotropical perspective. Smithsonian Institution Press, Washington, D.C.

RAPPOLE, J. \& JONES, P. (2002). Evolution of old and new world migration systems. Ardea 90, 525-537.

RAPPOLE, J. \& TiPtON, A. (1992). The evolution of avian migration in the Neotropics. Ornitología Neotropical 3, 45-55.

ReE, R.H., Moore, B.R., WebB, C.O. \& Donoghue, M.J. (2005). A likelihood framework for inferring the evolution of geographic range on phylogenetic trees. Evolution 59, 2299-2311.

Reudink, M.W., MARRA, P.P., KYSER, T.K., BoAg, P.T., LANGin, K.M. \& RATClifFe, L.M. (2009). Non-breeding season events influence sexual selection in a long-distance migratory bird. Proceedings of the Royal Society of London B: Biological Sciences 276, 1619-1626.

Rolland, J., Jiguet, F., Jønsson, K.A., Condamine, F.L. \& Morlon, H. (2014). Settling down of seasonal migrants promotes bird diversification Settling down of seasonal migrants promotes bird diversification. Proceedings of the Royal Society B: Biological Sciences 281, 20140473.

This article is protected by copyright. All rights reserved. 
Rubenstein, D., Chamberlain, C., Holmes, R., Ayres, M., Waldbauer, J., Graves, G. \& TUROSS, N. (2002). Linking breeding and wintering ranges of a migratory songbird using stable isotopes. Science 295, 1062-1065.

RUEGG, K. (2008). Genetic, morphological, and ecological characterization of a hybrid zone that spans a migratory divide. Evolution 62, 452-466.

RuEGG, K.C. \& SMith, T.B. (2002). Not as the crow flies: a historical explanation for circuitous migration in Swainson's Thrush (Catharus ustulatus). Proceedings of the Royal Society B: Biological Sciences 269, 1375.

RUF, T. \& GEISER, F. (2015). Daily torpor and hibernation in birds and mammals. Biological Reviews 90, 891-926.

Rushing, C.S., Dudash, M.R., Studds, C.E. \& MARRA, P.P. (2015). Annual variation in longdistance dispersal driven by breeding and non-breeding season climatic conditions in a migratory bird. Ecography 38, 1006-1014.

SAFRIEL, U. (1995). The evolution of palearctic migration: The case for southern ancestry. Israel Journal of Zoology 41, 417-431.

SALEWSKI, V. \& BRUDERER, B. (2007). The evolution of bird migration-a synthesis. Naturwissenschaften 94, 268-279.

Sayol, F., Maspons, J., Lapiedra, O., Iwaniuk, A.N., SzÉKely, T. \& Sol, D. (2016). Environmental variation and the evolution of large brains in birds. Nature Communications 7, 13971.

SCHLUTER, D. (2016). Speciation, ecological opportunity, and latitude. The American Naturalist 187, 1-18.

SENNER, N.R., Stager, M. \& Cheviron, Z.A. (2017). Spatial and temporal heterogeneity in climate change limits species' dispersal capabilities and adaptive potential. Ecography 40, $1-12$.

SHAw, A.K. (2016). Drivers of animal migration and implications in changing environments. Evolutionary Ecology 30, 991-1007.

Sherry, D.F., VACCARINO, A.L., BuCKenham, K. \& HerZ, R.S. (1989). The hippocampal complex of food-storing birds. Brain, Behavior and Evolution 34, 308-317.

Shizuka, D., Chaine, A.S., Anderson, J., Johnson, O., LAursen, I.M. \& Lyon, B.E. (2014). Across-year social stability shapes network structure in wintering migrant sparrows. Ecology Letters 17, 998-1007.

Sillett, S.T., HolmeS, R.T. \& SHERry, T.W. (2000). Impacts of a global climate cycle on population dynamics of a migratory songbird. Science 288, 2040-2042.

Smith, B.T., Bryson Robert W, J., Houston, D.D. \& KlickA, J. (2012). An asymmetry in niche conservatism contributes to the latitudinal species diversity gradient in New World vertebrates. Ecology letters 15, 1318-1325.

Sol, D., Garcia, N., Iwaniuk, A., Davis, K., Meade, A., Boyle, W.A. \& Székely, T. (2010). Evolutionary divergence in brain size between migratory and resident birds. PLOS ONE 5, $1-8$.

This article is protected by copyright. All rights reserved. 
Sol, D., LefEBVRe, L. \& RodrigueZ-TeiJeiro, J.D. (2005). Brain size, innovative propensity and migratory behaviour in temperate Palaearctic birds. Proceedings of the Royal Society B: Biological Sciences 272, 1433-1441.

Somveille, M., ManicA, A., Butchart, S.H.M. \& Rodrigues, A.S.L. (2013). Mapping global diversity patterns for migratory birds. PLOS ONE $\mathbf{8}$.

Somveille, M., ManiCA, A. \& Rodrigues, A.S. (2018a). Where the wild birds go: explaining the differences in migratory destinations across terrestrial bird species. Ecography, 1-12.

Somveille, M., Rodrigues, A.S.L. \& MANiCA, A. (2015). Why do birds migrate? A macroecological perspective. Global Ecology and Biogeography 24, 664-674.

Somveille, M., Rodrigues, A.S.L. \& MANiCA, A. (2018b). Energy efficiency drives the global seasonal distribution of birds. Nature Ecology and Evolution 2, 962-969.

Stager, M., Pollock, H.S., Benham, P.M., Sly, N.D., Brawn, J.D. \& Cheviron, Z.A. (2016). Disentangling environmental drivers of metabolic flexibility in birds: the importance of temperature extremes versus temperature variability. Ecography 39, 787-795.

StAmPS, J., KRISHNAN, V. V. \& REID, M.L. (2005). Search costs and habitat selection by dispersers. Ecology 86, 510-518.

StudDS, C.E., KYSER, T.K. \& MARRA, P.P. (2008). Natal dispersal driven by environmental conditions interacting across the annual cycle of a migratory songbird. Proceedings of the National Academy of Sciences of the United States of America 105, 2929.

Stutchbury, B.J. \& Robertson, R.J. (1990). Do Tree Swallows use nest cavities as night roosts during territory establishment? Journal of Field Ornithology 61, 26-33.

SWANSON, D.L. \& GARLAND, T. (2009). The evolution of high summit metabolism and cold tolerance in birds and its impact on present-day distributions. Evolution 63, 184-194.

SWANSON, D.L. \& VÉZINA, F. (2015). Environmental, ecological and mechanistic drivers of avian seasonal metabolic flexibility in response to cold winters. Journal of Ornithology 156, 377-388.

Thomson, A.L. (1926). Problems of bird-migration. Houghton Mifflin, Boston.

Thorup, K., Tøttrup, A.P., Willemoes, M., KlaAssen, R.H.G., StrandBerG, R., Vega, M.L., DASARI, H.P. \& ARAÚJO, M.B. (2017). Resource tracking within and across continents in long-distance bird migrants. Science Advances 3, e1601360.

TOEWS, D.P.L. (2017). Habitat suitability and the constraints of migration in New World warblers. Journal of Avian Biology 48, 1-10.

TURBEK, S.P., ScORDATO, E.S.C. \& SAFRAN, R.J. (2017). The role of seasonal migration in population divergence and reproductive isolation. Trends in Ecology and Evolution 33, 164-175.

VAN VALEN, L. (1973). A new evolutionary law. Evolutionary Theory 1, 1-30.

WALlaCE, A.R. (1874). Migration of birds. Nature 10, 459.

Webster, M.S., MARrA, P.P., HAig, S.M., BensCh, S. \& Holmes, R.T. (2002) Links between worlds: Unraveling migratory connectivity. Trends in Ecology and Evolution 17, 76-83.

West-Eberhard, M.J. (2003). Developmental plasticity and evolution. Oxford University Press, 
New York, NY.

Wetmore, A. (1930). The Migrations of Birds. Harvard University Press, Cambridge, MA.

WiEns, J.J. \& DonoghuE, M.J. (2004). Historical biogeography, ecology and species richness.

Trends in ecology \& evolution 19, 639-644.

Williams, C.M., Ragland, G.J., Betini, G., Buckley, L.B., Cheviron, Z.A., Donohue, K., Hereford, J., Humphries, M.M., Lisovski, S., Marshall, K.E., Schmidt, P.S., Sheldon, K.S., VARPE, Ø. \& VISSER, M.E. (2017). Understanding evolutionary impacts of seasonality: An introduction to the symposium. Integrative and Comparative Biology 57, 921-933.

WiLliAMS, E.J. \& BOYLE, W.A. (2018). Patterns and correlates of within-season breeding dispersal: A common strategy in a declining grassland songbird. The Auk 135, 1-14.

WingER, B.M., BARKER, F.K. \& REE, R.H. (2014). Temperate origins of long-distance seasonal migration in New World songbirds. Proceedings of the National Academy of Sciences of the United States of America 111, 12115-12120.

Winger, B.M., LOVETTE, I.J. \& WINKLER, D.W. (2012). Ancestry and evolution of seasonal migration in the Parulidae. Proceedings of the Royal Society B: Biological Sciences 279, 610-618.

WINKER, K. (2010). On the origin of species through heteropatric differentiation: A review and a model of seciation in migratory animals. Ornithological Monographs 69, 1-30.

Winker, K. \& PRUETT, C. (2006). Seasonal migration, speciation, and morphological convergence in the genus Catharus (Turdidae). Auk 123, 1052-1068.

WINKLER, D.W. (2005). How do migration and dispersal interact. In Birds of Two Worlds: the Ecology and Evolution of Migration pp. 401-413.

Winkler, D.W., Gandoy, F.A., Areta, J.I., Iliff, M.J., RakhimberdieV, E., Kardynal, K.J. \& HoBSON, K.A. (2017). Long-distance range expansion and rapid adjustment of migration in a newly established population of Barn Swallows breeding in Argentina. Current Biology 27, 1080-1084.

WinKLER, H., LEISLER, B. \& BERNROIDER, G. (2004). Ecological constraints on the evolution of avian brains. Journal of Ornithology 145, 238-244.

WiTYNSKI, M.L. \& BonTER, D.N. (2018). Crosswise migration by Yellow Warblers , NearcticNeotropical passerine migrants. Journal of Field Ornithology 89, 37-46.

ZIMMER, K. \& IsLER, M.L. (2003). Family Thamnophilidae (Typical Antbirds). In Handbook of the Birds of the World Volume 8: Broadbills to Tapaculos (eds J. DEL HoYO, A. ElLIOT \& D. CHRISTIE), pp. 448-681. Lynx Edicions, Barcelona, Spain.

ZINK, R. (2002). Towards a framework for understanding the evolution of avian migration. Journal of Avian Biology 33, 433-436.

ZINK, R.M. (2011). The evolution of avian migration. Biological Journal of the Linnean Society 104, 237-250.

ZINK, R.M. \& GARDNER, A.S. (2017). Glaciation as a migratory switch. Science Advances 3, 19. 
ZúÑiga, D., Gager, Y., KokKo, H., Fudickar, A.M., Schmidt, A., Neaf-Daenzer, B., WiKelsKi, M. \& PARTECKE, J. (2017). Migration confers winter survival benefits in a partially migratory songbird. eLife $\mathbf{6}$.

Zurell, D., Gallien, L., Graham, C.H. \& Zimmermann, N.E. (2018). Do long-distance migratory birds track their niche through seasons? Journal of Biogeography 45, 1459-1468. 


\section{FIGURE CAPTIONS}

Fig. 1. The evolution of migration in response to seasonality. (A) Migration may evolve following dispersal into a seasonal environment. Our depiction builds on fig. 2 from Salewski \& Bruderer (2007). Panel 1: individuals that are found in relatively aseasonal environments, or the offspring of these individuals, may disperse (arrows) into environments that are more seasonal in the course of regular, undirected searches for new breeding locations. Panel 2: when seasonal conditions deteriorate in the newly occupied region (i.e. during winter), individuals (orange) that escape via movement (dashed arrow) to a more hospitable non-breeding territory (blue) may have a better chance of survival. Panel 3: owing to the selective benefits of breeding-site fidelity, selection will favour individuals that return to their previous breeding region, and thus migration (dashed arrows) will typically be favoured over nomadism in predictably fluctuating (i.e.

seasonal) environments. Alternatively, individuals that adopt a different adaptation to seasonality that does not involve movement, such as hibernation (pink), may also survive and breed again near their previous breeding location. However, individuals that do not display any physiological or behavioural modification for increased seasonality will not survive or will have lower fitness (red). Over time, either round-trip migrations (orange and blue) or adaptations such as hibernation (pink) may enable species to colonize yet more seasonal regions and the relative prevalence in a population of migration versus other adaptations to seasonality will depend on numerous factors including phylogenetic history, physiological constraints, and behavioural 
plasticity. (B) Similarly, migration may evolve in response to increased seasonality through time. As aseasonal environments become more seasonal across years, only individuals that migrate or evolve alternative adaptations to seasonality will persist.

Fig. 2. Variations in migratory strategy reveal alternative adaptations to seasonality. The diminutive Golden-crowned Kinglet (Regulus satrapa) breeds in boreal North America (red), with resident populations (purple) and wintering populations (blue) persisting year-round in harsh boreal environments. By contrast, Blackpoll Warblers (Setophaga striata) undergo an arduous migration from breeding grounds in boreal North America to wintering grounds in northern South America. White-throated Sparrows (Zonotrichia albicollis) migrate short distances to take advantage of the less-harsh winters in the southern USA. Images reproduced with permission from del Hoyo et al. (2018). 


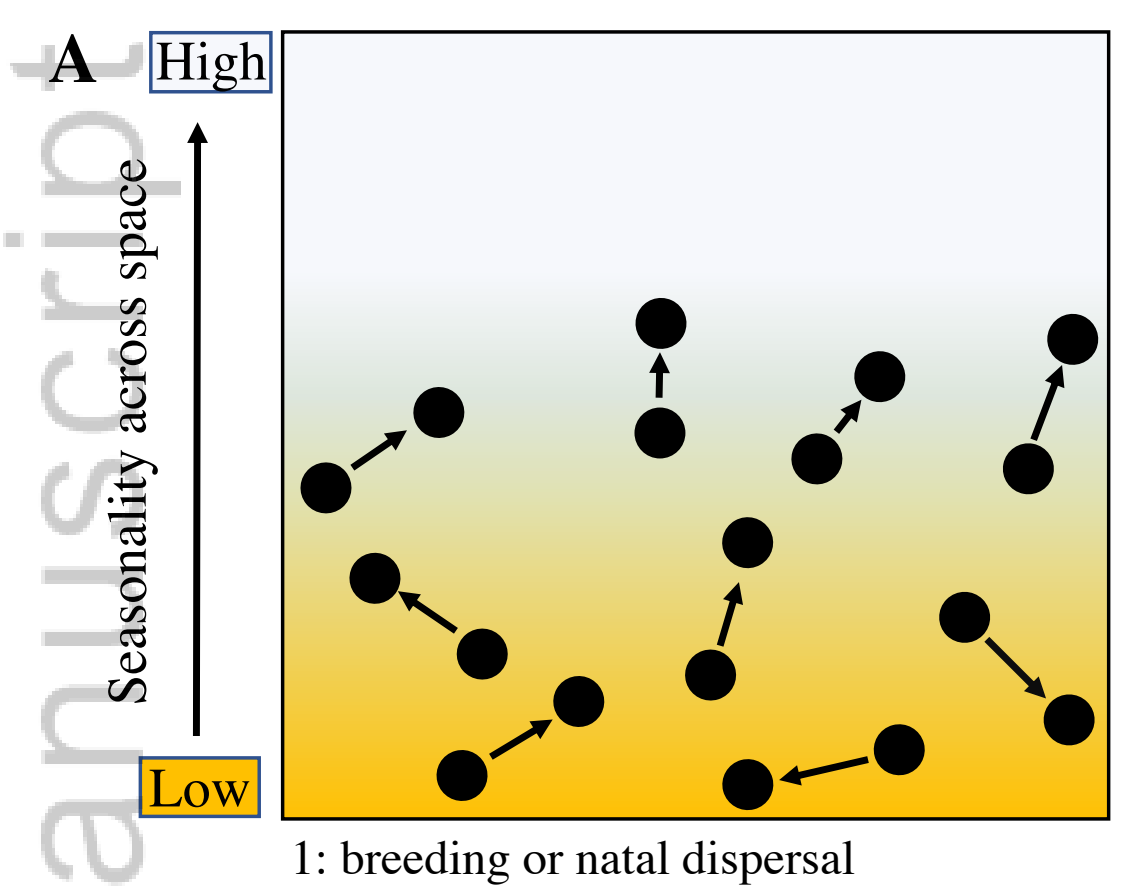

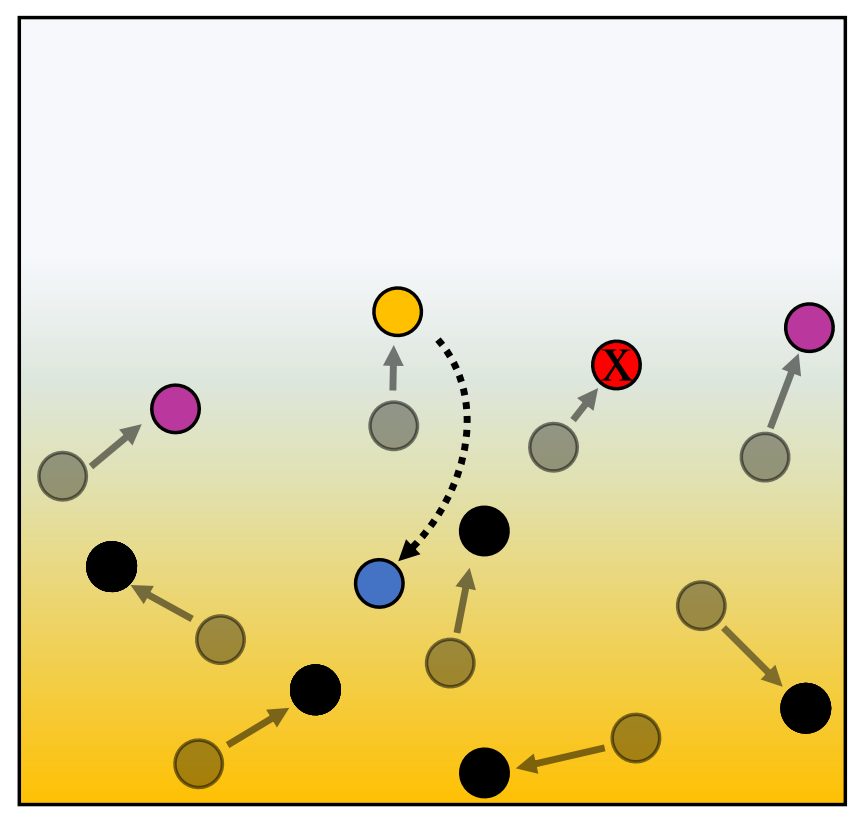

2: response to encountered seasonality

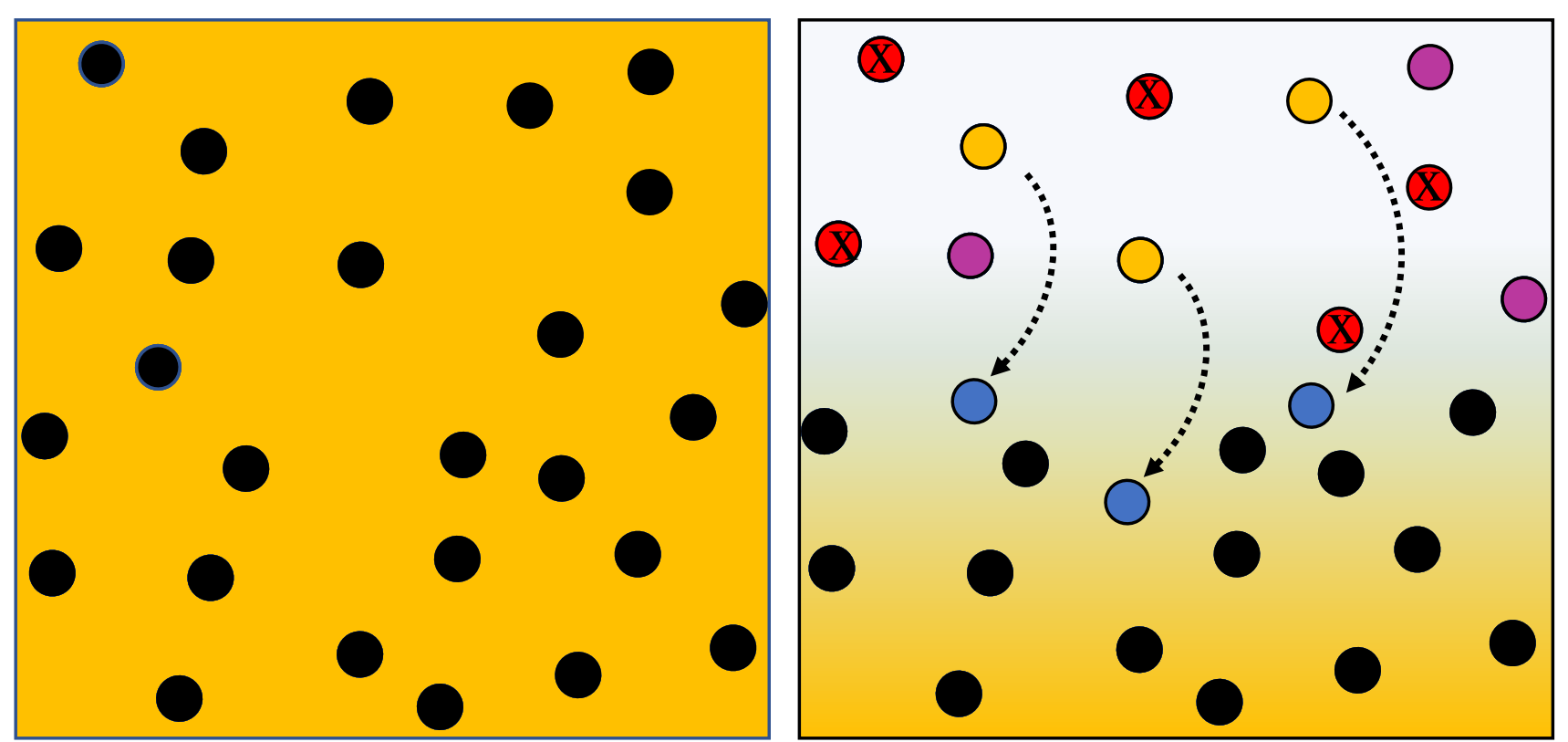

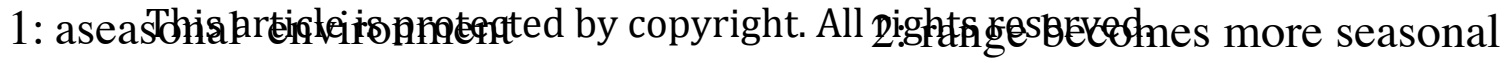

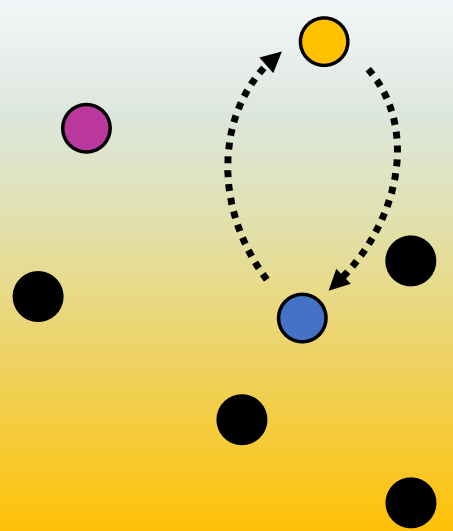

3: seasonally adapted populations

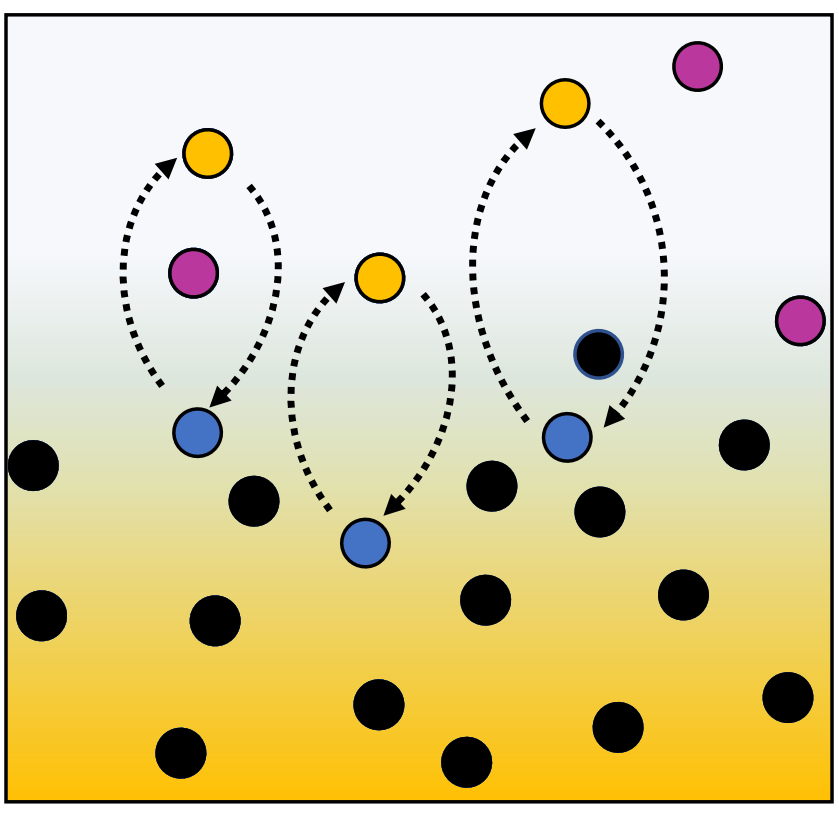

3: seasonally adapted populations 

Regulus satrapa

Setophaga striata

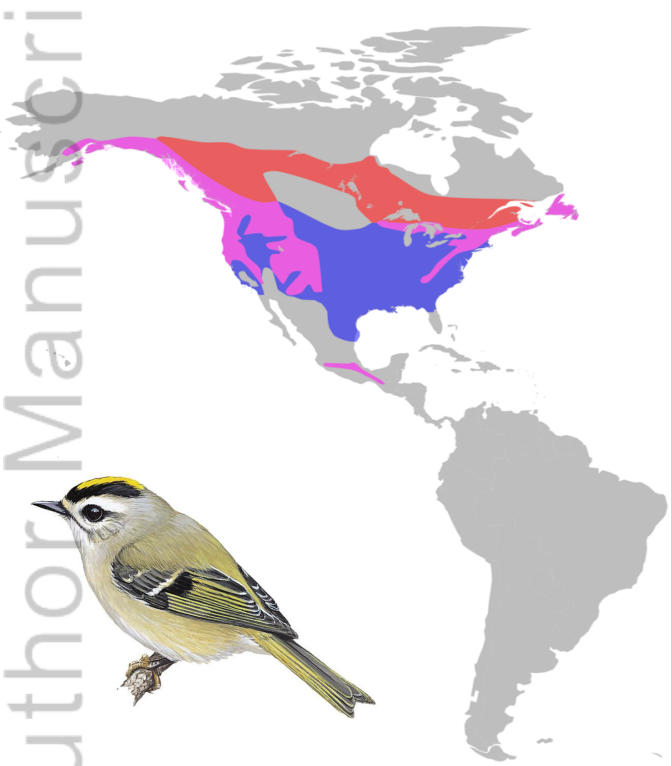

This article is protected by copyright. All rights reseryed.

\section{Zonotrichia albicollis}

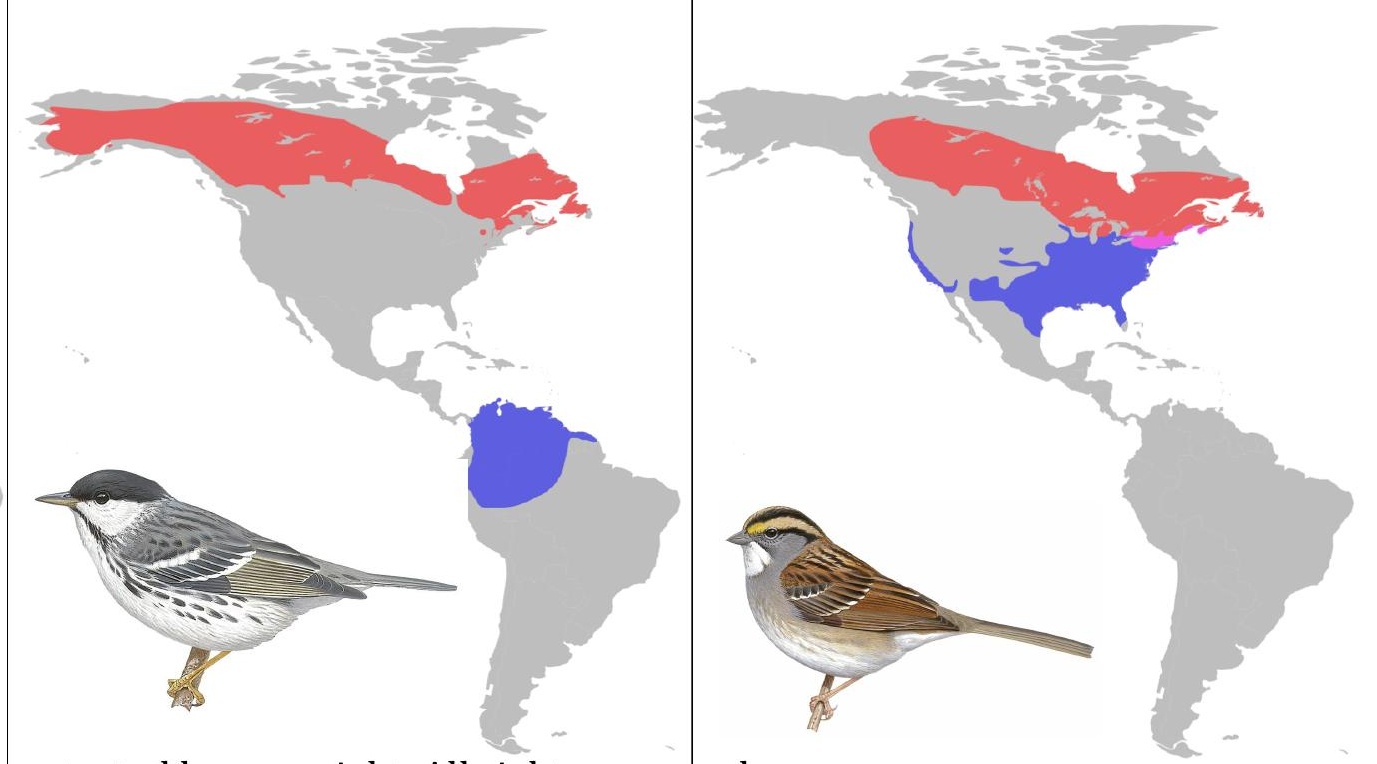

